\title{
Parameterization of Convective Transport in a Lagrangian Particle Dispersion Model and Its Evaluation
}

\author{
Caroline Forster* AND Andreas STOHL \\ Norwegian Institute for Air Research (NILU), Kjeller, Norway \\ Petra SeIBERT \\ Institute of Meteorology, University of Natural Resources and Applied Life Sciences (BOKU), Vienna, Austria
}

(Manuscript received 22 December 2005, in final form 28 July 2006)

\begin{abstract}
This paper presents the revision and evaluation of the interface between the convective parameterization by Emanuel and Živković-Rothman and the Lagrangian particle dispersion model "FLEXPART" based on meteorological data from the European Centre for Medium-Range Weather Forecasts (ECMWF). The convection scheme relies on the ECMWF grid-scale temperature and humidity and provides a matrix necessary for the vertical convective particle displacement. The benefits of the revised interface relative to its previous version are presented. It is shown that, apart from minor fluctuations caused by the stochastic convective redistribution of the particles, the well-mixed criterion is fulfilled in simulations that include convection. Although for technical reasons the calculation of the displacement matrix differs somewhat between the forward and the backward simulations in time, the mean relative difference between the convective mass fluxes in forward and backward simulations is below 3\% and can therefore be tolerated. A comparison of the convective mass fluxes and precipitation rates with those archived in the 40-yr ECMWF Reanalysis (ERA-40) data reveals that the convection scheme in FLEXPART produces upward mass fluxes and precipitation rates that are generally smaller by about $25 \%$ than those from ERA-40. This result is interpreted as positive, because precipitation is known to be overestimated by the ECMWF model. Tracer transport simulations with and without convection are compared with surface and aircraft measurements from two tracer experiments and to ${ }^{222} \mathrm{Rn}$ measurements from two aircraft campaigns. At the surface no substantial differences between the model runs with and without convection are found, but at higher altitudes the model runs with convection produced better agreement with the measurements in most of the cases and indifferent results in the others. However, for the tracer experiments only few measurements at higher altitudes are available, and for the aircraft campaigns the ${ }^{222} \mathrm{Rn}$ emissions are highly uncertain. Other datasets better suitable for the validation of convective transport in models are not available. Thus, there is a clear need for reliable datasets suitable to validate vertical transport in models.
\end{abstract}

\section{Introduction}

It has long been recognized that cumulus convection plays an important role in both atmospheric physics and

\footnotetext{
* Current affiliation: Deutsches Zentrum für Luft- und Raumfahrt (DLR), Institut für Physik der Atmosphäre, Weßling, Germany.

Corresponding author address: Caroline Forster, Deutsches Zentrum für Luft- und Raumfahrt (DLR), Institut für Physik der Atmosphäre, Oberpfaffenhofen, Postfach 1116, D-82230 Weßling, Germany.

E-mail: caroline.forster@dlr.de
}

chemistry (e.g., Smith 1997b). The sensible and latent heat fluxes from the land's surface and the ocean, which are both heated by the incoming solar radiation, tend to destabilize the lower atmosphere (e.g., Emanuel 1994). The result is convective overturning in the atmosphere that transports large amounts of mass and energy.

Although convection affects the dynamics and thermodynamics of large-scale atmospheric circulation, the convective clouds themselves are small scale in the horizontal plane. They are related to spatially variable sensible and latent heat fluxes from the earth's surface and have a horizontal extent on the order of kilometers (e.g., Cotton and Anthes 1992). In the vertical direction, they can extend throughout the whole tropo-

DOI: 10.1175/JAM2470.1

(C) 2007 American Meteorological Society 
sphere. Global-scale atmospheric models have a typical horizontal grid spacing of about $1^{\circ}$ and a vertical resolution on the order of tens of meters to kilometers. Thus, in such a model, convective clouds are grid scale in the vertical direction but are subgrid scale in the horizontal plane. Even if convection organizes itself, for example, in mesoscale convective systems or tropical cyclones with a horizontal dimension on the order of a couple of hundred kilometers (Cotton and Anthes 1992; Cotton et al. 1995), it is not sufficiently resolved. It has therefore to be parameterized-that is, convective temperature and humidity tendencies for the gridscale variables are introduced that depend on these variables and stabilize the profiles.

Observations show that convection is always accompanied by large-scale, low-level convergence of mass and moisture (Riehl and Malkus 1959; Frank 1978; Raymond 1995) and occurs in regions where the air is conditionally unstable to the pseudioadiabatic ascent of a surface air parcel (Emanuel 1994). However, the chain of causality for convection is not yet completely understood to date. There exist two ways of interpreting the role and influence of convection. According to theory 1 , the large-scale convergence of mass and moisture destabilizes the atmosphere and triggers convection (Charney and Eliassen 1964; Ooyama 1964); according to theory 2, the supply of energy (surface fluxes, etc.) destabilizes the atmosphere and the convergence of mass and moisture is rather a result of convection (Manabe and Strickler 1964; Arakawa and Schubert 1974; Emanuel et al. 1994). It is therefore not surprising that a large number of different convective parameterization schemes relying on the two theories have been developed. A summary and review of convective parameterizations can be found in Emanuel and Raymond (1993) and Arakawa (2004). The two theories have been discussed controversially in the literature (e.g., Ooyama 1982; Emanuel et al. 1994; Smith 1997a) but were both successful in, for example, simulating the development of tropical cyclones (Ooyama 1969; Emanuel 1986).

Convection does not only affect the atmospheric dynamics and thermodynamics, but also transports large amounts of mass. Cotton et al. (1995) estimate a global annual mass flux of $4.95 \times 10^{19} \mathrm{~kg}$ of boundary layer air by convection, which represents a venting of the entire boundary layer about 90 times per year. Convection thus effectively redistributes chemical substances in the vertical direction, which is particularly important for substances that do not have a uniform distribution. The substances can rapidly be transported from the boundary layer to the upper troposphere where they can influence the chemistry (e.g., Lelieveld and Crutzen
1994) and be subject to long-range transport (e.g., Stohl and Trickl 1999). Therefore, convection has to be represented in models of atmospheric transport and chemistry (Feichter and Crutzen 1990).

In this paper we present the evaluation of a convective parameterization scheme in the Lagrangian tracer transport model "FLEXPART," version 6.2 (Stohl et al. 2005). Primarily for practical reasons described in section $2 \mathrm{~b}$, a convection scheme based on theory 2 was chosen. It is tested with respect to the well-mixed criterion (section 3) and its robustness toward simulations forward and backward in time (section 4). In addition, its convective mass fluxes and the convective precipitation rates are compared with those of the 40-yr reanalysis project (ERA-40; Kållberg et al. 2005) from the European Centre for Medium-Range Weather Forecasts (ECMWF) (section 5). FLEXPART simulations are compared with data from two tracer experiments (section 6) and with ${ }^{222} \mathrm{Rn}$ measurements from two aircraft campaigns (section 7).

\section{Model description}

In a Lagrangian particle model the trajectories of a multitude of particles are calculated to describe the dispersion of atmospheric tracers from point, line, area, or volume sources. These particles do not necessarily represent real particles, but infinitesimally small air parcels. Each particle is carrying a mass fraction of a tracer. The accuracy of the simulation depends therefore on the number of particles used, and with the number of particles $N \rightarrow \infty$ the computation converges toward the exact solution. Several different tracer masses can be carried by each particle. The computational cost of the advection scheme is therefore independent of the number of tracers transported. Moreover, Lagrangian models do not suffer from numerical diffusion. This is a clear advantage to Eulerian approaches that use a grid and finite differences or spectral techniques. These approaches work well when applied to smoothly varying tracer fields but can result in considerable numerical diffusion in the presence of tracer fields with strong gradients. Note, however, that the accuracy of the tracer fields in Lagrangian models depends on the method used to calculate the concentrations. Last, in an Eulerian model a tracer released from a point source is instantaneously mixed within the entire grid box, whereas a Lagrangian model is independent of a computational grid.

\section{a. General description of FLEXPART}

The Lagrangian particle dispersion model FLEXPART, version 6.2 (Stohl et al. 2005), simulates the mesoscale 
and long-range transport and dispersion of nonreactive tracers and has been used in a number of studies on long-range transport of air pollution (e.g., Wotawa and Trainer 2000; Forster et al. 2001, 2004; Spichtinger et al. 2001). It parameterizes turbulence in the boundary layer and in the free troposphere by solving Langevin equations (Stohl and Thomson 1999), can simulate dry and wet deposition as well as radioactive decay, and includes a moist convective parameterization scheme (evaluated within this study). Forward and backward simulations in time are both possible with FLEXPART. FLEXPART, version 6.2, presented here, can be driven either with model-level data from the ECMWF or with pressure-level data from the National Centers for Environmental Prediction (NCEP) Global Forecast System (GFS). In this study we use operational ECMWF data and data from the ERA-40 project (Kållberg et al. 2005). They have a temporal resolution of $3 \mathrm{~h}$ (analyses at 0000, 0600, 1200, and 1800 UTC and 3-h forecasts at 0300, 0900, 1500, and 2100 UTC) and were extracted with a horizontal resolution of $1^{\circ} \times 1^{\circ}$ on 60 levels that follow the terrain near the surface and the pressure at the upper levels with a transition zone in between. The convection scheme in FLEXPART has also been tested with NCEP GFS data. The results of these simulations were similar to those based on ECMWF data and are not presented here.

\section{b. The convection scheme and its implementation into FLEXPART}

Under convective conditions, the turbulence in the vertical direction is highly inhomogeneous and skewed, that is, the downdrafts occupy larger areas than the updrafts. In the boundary layer such turbulent convective motions can be parameterized by a Lagrangian technique by solving Langevin equations, for example, under the assumption of bi-Gaussian turbulence (e.g., Luhar et al. 1996). However, it is not straightforward to apply such a parameterization to moist convection that can extend throughout the entire troposphere. The parameters needed for developing a Langevin equation are not known for deep convection, and, to the knowledge of the authors, no Langevin equation for moist deep convection has been developed to date. The few Lagrangian models accounting for deep convection go back to a traditional approach when parameterizing convection and use convective mass fluxes on an Eulerian grid for the vertical redistribution of the particles (e.g., Collins et al. 2002; Reithmeier and Sausen 2002). We also chose an existing (Eulerian) convective parameterization scheme for FLEXPART.

Seibert et al. (2001) equipped FLEXPART with the convective parameterization scheme by Emanuel and
Živković-Rothman (1999, hereinafter called the EZ99 scheme). The motivation to use this scheme for FLEXPART was that it relies on the grid-scale temperature and humidity fields only (which are provided by the input data) and gives as a by-product the convective tendencies of tracers. The tracer tendencies for each column are given on the same levels as the input data and are calculated from a vertical mass displacement matrix in the respective column. In the implementation by Seibert et al. (2001) these Eulerian tracer tendencies were used to determine the convective displacements of particles. This version was applied successfully, for example, in the studies by James et al. (2003a,b). However, the convection added a significant burden to the computation time (up to $90 \%$ of FLEXPART's computation time), because it scaled to the third power with the number of vertical model levels. In addition, unavoidable numerical errors were introduced when calculating the Eulerian tracer tendencies.

Therefore, the interface between FLEXPART and the EZ99 scheme has been completely revised. In the revised version presented here, we no longer use the tracer tendencies provided by the EZ99 scheme to determine the convective displacements of particles. Instead, we use directly the mass fluxes given by the vertical displacement matrix and compile them to probabilities by which the particles are randomly displaced. In addition, in the Seibert et al. (2001) version the convective displacement of particles was only performed whenever new temperature and specific humidity profiles required as input to the EZ99 scheme were read in from the ECMWF data (typically $3 \mathrm{~h}$ ). In the version presented here the EZ99 scheme is called every FLEXPART synchronization time step (typically 900 s), and the ECMWF temperature and specific humidity profiles are interpolated to the current time. After these revisions the convection scheme accounts for less computation time than before, because the calculation of the tracer tendencies is skipped, and thus the convection scales to the square instead of the third power with the number of vertical model levels. In a transport simulation with 20 million particles well distributed over the entire hemisphere the convection consumes about $30 \%$ of the computation time. For a global run with 2 times as many particles, it may consume up to $70 \%$ of the computation time. Moreover, by directly using the vertical displacement matrix for the particle redistribution, we avoid numerical errors.

\section{1) Description of THE EZ99 SCHEME}

In the EZ99 scheme, convection in a grid cell is triggered whenever $T_{\mathrm{vp}}^{\mathrm{LCL}+1} \geq T_{v}^{\mathrm{LCL}+1}+\delta T$, where $T_{\mathrm{vp}}$ is 
the virtual temperature of a surface air parcel, LCL is the lifting condensation level of a surface air parcel, $\mathrm{LCL}+1$ is the level above the LCL, $T_{v}$ is the virtual temperature of the environment, and $\delta T=0.9 \mathrm{~K}$ is the required excess temperature. Convection then acts among the cloud base, LCL, and the level of neutral buoyancy LNB. Based on the buoyancy sorting principle (Telford 1975; Raymond and Blyth 1986; Emanuel 1991) a matrix $M_{i, j}$ of the saturated upward and downward mass fluxes within clouds is then calculated between LCL and LNB by accounting for entrainment and detrainment:

$$
M_{i, j}=\frac{M_{i}\left(\left|\sigma_{i, j+1}-\sigma_{i, j}\right|+\left|\sigma_{i, j}-\sigma_{i, j-1}\right|\right)}{\left(1-\sigma_{i, j}\right) \sum_{j=\mathrm{LCL}}^{\mathrm{LNB}}\left(\left|\sigma_{i, j+1}-\sigma_{i, j}\right|+\left|\sigma_{i, j}-\sigma_{i, j-1}\right|\right)} .
$$

Here $M_{i, j}$ are the mass fractions displaced from source level $i$ to destination level $j, M_{i}$ is the mass fraction displaced from the surface to level $i$, and $0<\sigma_{i, j}<1$ is the mixing fraction between level $i$ and level $j$. The fraction $\sigma_{i, j}$ is determined by the environmental potential temperature $\theta_{j}$, the liquid potential temperature $\theta_{i, j}^{l}$ of air displaced adiabatically from $i$ to $j$, and the liquid potential temperature $\theta_{i, j}^{\mathrm{lp}}$ of an air parcel first lifted adiabatically to level $i$ and farther to level $j$ :

$$
\sigma_{i, j}=\frac{\theta_{j}-\theta_{i, j}^{\mathrm{lp}}}{\theta_{i, j}^{l}-\theta_{i, j}^{\mathrm{lp}}} .
$$

More details on Eqs. (1) and (2), which involve assumptions on precipitation processes, can be found in Emanuel (1991). The mass fractions $M_{i}$ are proportional to the magnitude of the convective cloud base upward mass flux

$$
\begin{aligned}
M_{\mathrm{cb}}(t)= & (1-\beta) M_{\mathrm{cb}}(t-1)+0.1 \alpha\left[T_{\mathrm{vp}}^{\mathrm{LCL}+1}(t)\right. \\
& \left.-T_{v}^{\mathrm{LCL}+1}(t)+\delta T\right],
\end{aligned}
$$

where $t$ is the current time and $t-1$ is the previous time. Here $\alpha=0.025$ and $\beta=0.1$ are tuning parameters controlling the magnitude of $M_{\mathrm{cb}}(t)$. They were chosen such that an internal Courant-Friedrichs-Levy criterion is fulfilled within the EZ99 scheme. At the beginning of a model run, $M_{\mathrm{cb}}(t-1)$ is set to zero. There are a number of other parameters in the EZ99 scheme controlling, for example, precipitation processes and the rates of entrainment and detrainment in the cloud. We did not change these parameters, but took them as suggested by the EZ99 scheme.

\section{2) INTERface BETWEen FLEXPART AND THE EZ99 SCHEME}

Every FLEXPART synchronization time step (typically 900 s), the EZ99 scheme is called and the particles are randomly redistributed according to the mass fluxes given by the matrix $M_{i, j}$. The temperature and specific humidity profiles required as input to the EZ99 scheme are taken from ECMWF data every $3 \mathrm{~h}$ and interpolated to the current time. For the vertical redistribution of particles according to the matrix $M_{i, j}$ in each convectively active column we revert back to a Lagrangian method. If the mass per square meter of an ECMWF model layer $i$ is $m_{i}=\left(p_{i-1 / 2}-p_{i+1 / 2}\right) / g_{\text {earth }}$ (where $p_{i-1 / 2}$ is the pressure one-half level below $i, p_{i+1 / 2}$ is the pressure one-half level above $i$, and $g_{\text {earth }}=9.81 \mathrm{~m} \mathrm{~s}^{-2}$ is the earth acceleration) and the mass flux from layer $i$ to layer $j$ accumulated over one time step is $\Delta t M_{i, j}$, then the probability of a particle to be moved from layer $i$ to layer $j$ is $\Delta t M_{i, j} / m_{i}$. An example of such a probability matrix for tropical convection is given in Fig. 1. It is most probable that a particle stays at its original layer, and there is high probability that a particle is displaced from the boundary layer to the middle or upper troposphere. The latter represents the typical property of deep tropical convection to transport air quickly from the boundary layer to the tropopause region (Emanuel 1994). At each source level $i$, the sum of the probabilities over all destination levels $j$ is 1 . Whether a given particle is displaced is determined by drawing a random number from the interval $[0,1]$. The probabilities at level $i$ are successively summed up over the $j$ levels starting at the lowest level. The particle will be displaced to that level $j$ at which this sum exceeds the random number for the first time. The random number also determines the exact position of the particle within its destination layer $j$ by interpreting the random number as the fraction of the distance from the lower boundary of this layer.

The matrix $M_{i, j}$ given in Eq. (1) is not balanced with respect to the mass redistribution, because it only accounts for saturated up- and downdrafts in the convective cell. We therefore assume that these up- and downdrafts are compensated by a subsidence mass flux in the cloud-free environment, a well known effect of convection in the real atmosphere. At each level $i$, the up- and downdrafts are determined from $M_{i, j}$ by summing up over all levels $j$. The subsidence mass fluxes are equal to these up- and downdrafts but with negative sign. After the convective redistribution of the particles according to $M_{i, j}$, the compensating subsidence mass fluxes are converted to a vertical velocity and act on those particles in the grid box that have not been convectively 

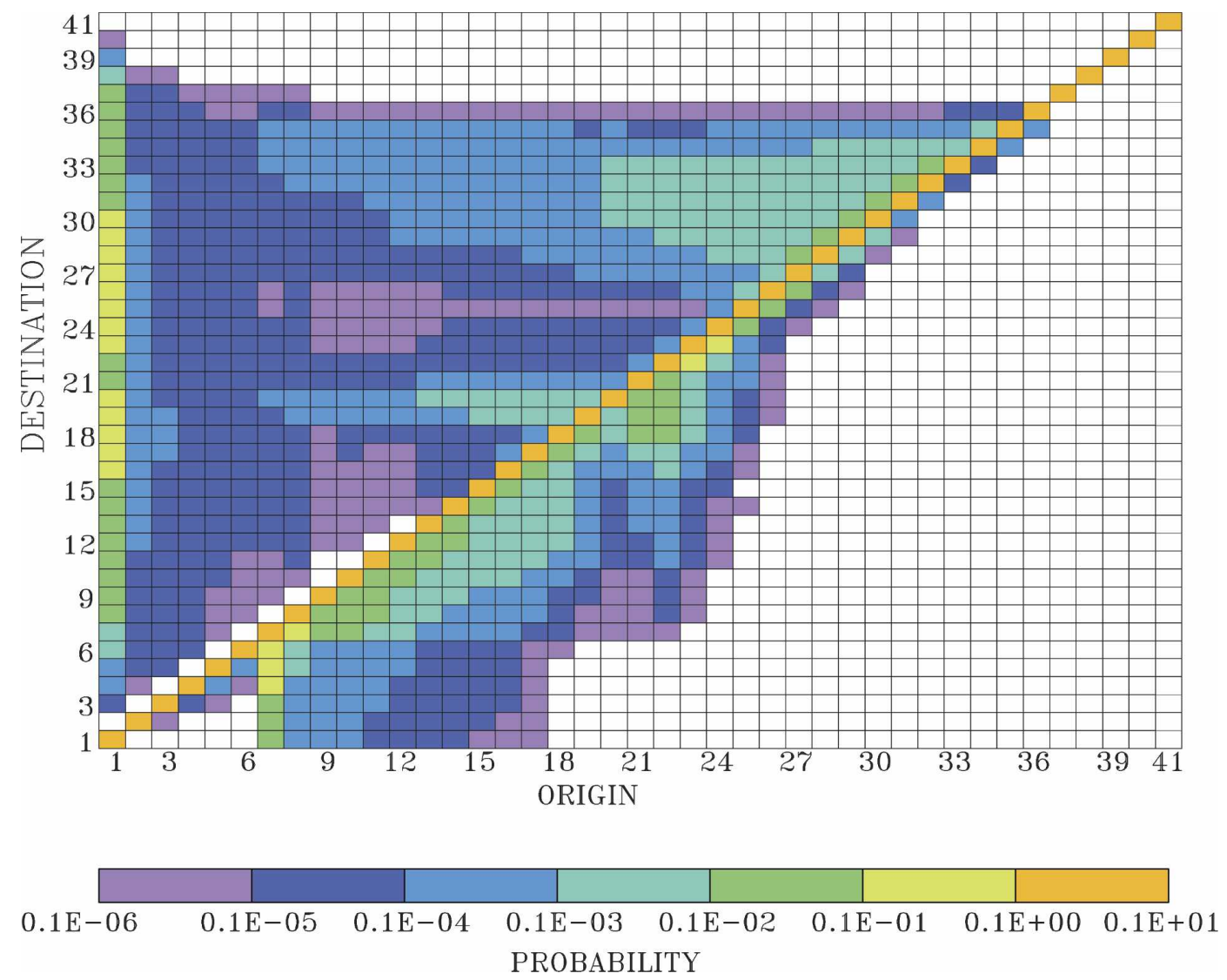

FIG. 1. Example of a mean convective redistribution matrix along $10^{\circ}$ latitude for October 1983 calculated from the EZ99 scheme. The colors indicate the probability for a particle to be displaced from its origin to its destination level. White colors indicate probabilities below $10^{-6}$. The sum of each column is 1 . Origin and destination are given in numbers of model levels. For the height of these model levels, see Table 1.

displaced. By calculating a subsidence velocity rather than displacing particles randomly between layers, the EZ99 scheme's numerical diffusion in the cloud-free environment is eliminated.

\section{Well-mixed criterion}

The implementation of the EZ99 scheme into FLEXPART was tested with regard to the so-called well-mixed criterion (Thomson 1987), which is fulfilled if particles that are well mixed in an atmospheric column remain so after the convective redistribution; that is, the particles must not accumulate or leave gaps in particular regions. Several single-column test runs over a time period of 1 month were performed with particles carrying an equal fraction of the atmospheric mass and initially distributed according to the air density. Only convection was allowed to act on the particles, not advection. In addition, constant meteorological conditions (those of 0000 UTC 1 June 2004, from ECMWF operational data) at a convectively active grid box over the
Gulf of Mexico $\left(25^{\circ} \mathrm{N}, 95^{\circ} \mathrm{W}\right)$ were applied over a 1-month period to avoid variations of the mass profiles resulting from the meteorological conditions. Here we show results from a test run with 600 particles per col-

TABLE 1. Height $(\mathrm{m})$ of the model levels (assuming standard pressure at the surface) for the matrix displayed in Fig. 1.

\begin{tabular}{cccccc}
\hline \hline Level & Height $(\mathrm{m})$ & Level & Height $(\mathrm{m})$ & Level & Height $(\mathrm{m})$ \\
\hline 1 & 8 & 15 & 1980 & 29 & 9173 \\
2 & 28 & 16 & 2309 & 30 & 9890 \\
3 & 58 & 17 & 2667 & 31 & 10654 \\
4 & 102 & 18 & 3054 & 32 & 11445 \\
5 & 161 & 19 & 3470 & 33 & 12296 \\
6 & 268 & 20 & 3915 & 34 & 13200 \\
7 & 335 & 21 & 4389 & 35 & 14151 \\
8 & 453 & 22 & 4893 & 36 & 15143 \\
9 & 595 & 23 & 5427 & 37 & 16172 \\
10 & 760 & 24 & 5989 & 38 & 17247 \\
11 & 950 & 25 & 6578 & 39 & 18375 \\
12 & 1166 & 26 & 7191 & 40 & 19558 \\
13 & 1409 & 27 & 7828 & 41 & 20769 \\
14 & 1681 & 28 & 8488 & & \\
\hline
\end{tabular}




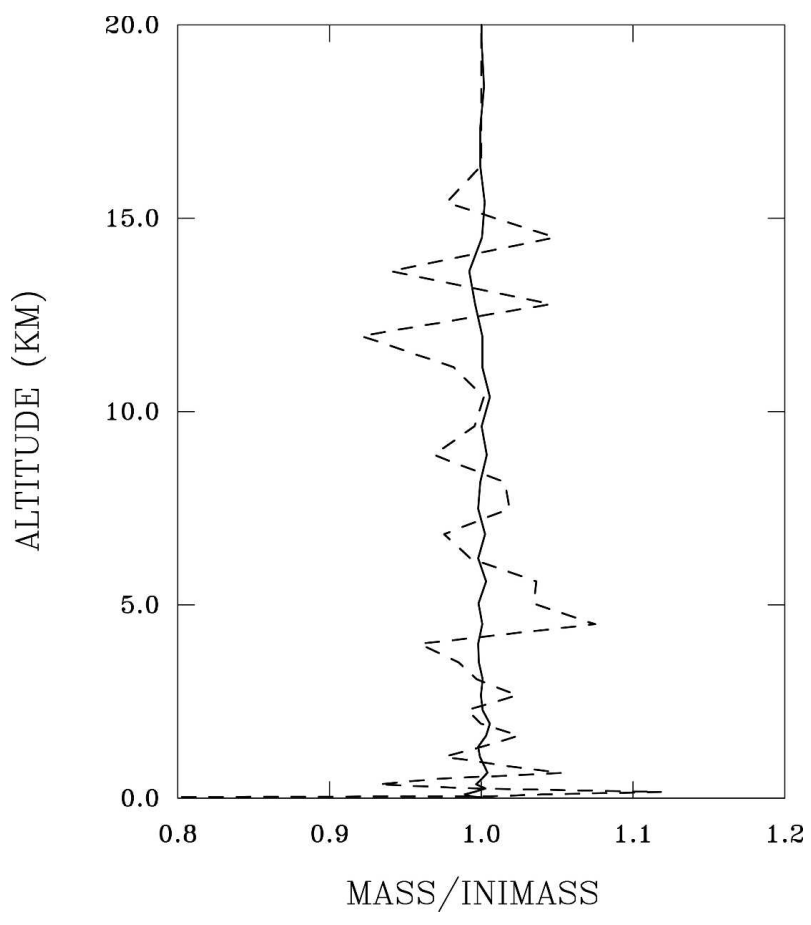

FIG. 2. Mass profile averaged over 1 month relative to the initial mass profile for 600 (dashed curve) and 250000 (solid curve) particles in an atmospheric column.

umn and another one with 250000 particles per column. Six-hundred particles is an example for a typical particle number per column in a transport simulation with 20 million particles that are well distributed over the entire hemisphere. In the case with 600 particles, the mass profiles averaged over 1 month can deviate from the initial mass profile by up to $10 \%$ (dashed curve in Fig. 2). The deviations are largest near the ground and at altitudes above $10 \mathrm{~km}$ and are caused by purely stochastic effects. Layers near the ground (very thin layers) and at altitudes above $10 \mathrm{~km}$ (low air density) contain only a very few particles. Therefore, if convection acts, it happens that all particles are removed from a layer or that a layer containing, for example, only one particle receives another one, leading to a doubling of the mass (and an instantaneous deviation of $100 \%$ from the initial mass profile) in this layer. These stochastic effects decrease substantially with a larger number of particles. For instance, with 250000 particles per column, the deviations from the initial mass profile are below $2 \%$ (solid curve in Fig. 2), and with the particle number $N \rightarrow \infty$, the deviations converge to zero. It can therefore be concluded that the well-mixed criterion is fulfilled in FLEXPART. In addition, because the stochastic effects cause errors below $2 \%$ for the case with 250000 particles and below $10 \%$ in the case with 600 particles, they are small enough that they can be tolerated.

\section{Comparison between forward and backward simulations}

Backward simulations are useful to calculate sourcereceptor relationships describing the sensitivity of a receptor to a source (Seibert and Frank 2004). Such simulations are computationally more efficient than forward simulations, if the number of receptors is smaller than the number of sources considered.

If FLEXPART is applied backward in time, all advective processes acting on the particles have to be reversed. Thus, in the convection scheme, the particles must be redistributed from their destination level back to their source level. The transposed redistribution matrix $M_{i, j}^{\mathrm{T}}$ has to be used and the probability of a particle having arrived at its present level from another level has to be considered. In addition, the compensating subsidence velocity acting on those particles that were not redistributed by $M_{i, j}^{\mathrm{T}}$ has to be reversed.

To derive the matrix $M_{i, j}, M_{\mathrm{cb}}$ from the previous time step must be known; that is, in the forward mode $M_{\mathrm{cb}}(t-1)$ is used to calculate $M_{\mathrm{cb}}(t)$ and $M_{i, j}(t)$. In the backward mode, however, $M_{\mathrm{cb}}(t)$ is known while $M_{\mathrm{cb}}(t-1)$ is not known, because we are coming from the other direction in time. The correct solution of this problem would be to run the convection scheme forward in time, store $M_{\mathrm{cb}}$ at each grid box and time step, and read it in, if the model is run backward. However, this solution is very impractical. Therefore, we simply reverse the procedure from the forward simulation, if the model is run backward in time, and use $M_{\mathrm{cb}}(t+1)$ instead of $M_{\mathrm{cb}}(t-1)$ to calculate $M_{\mathrm{cb}}(t)$ and $M_{i, j}^{\mathrm{T}}(t)$. We have to admit that this procedure would be physically correct only in a stationary atmosphere. In a real atmosphere, this procedure leads to differences between the forward and the backward $M_{\mathrm{cb}} \mathrm{s}$ and redistribution matrices $M_{i, j}$, and the $M_{\mathrm{cb}} \mathrm{s}$ are unphysical in the backward mode. This procedure can only be empirically justified if the error introduced is small.

We examined the error by comparing the forward and backward convective mass fluxes globally over a period of 1 month (October 1983, ERA-40 data). The mass fluxes were accumulated over a period of $6 \mathrm{~h}$ and stored every $6 \mathrm{~h}$. We compared the monthly mean of the mass fluxes as well as the mass fluxes at distinct times. As an example, Fig. 3 shows the monthly mean mass fluxes for each horizontal grid box summed up over all model levels obtained from the forward and backward simulations, respectively. Except for small mass fluxes $\left[<25 \mathrm{~g}\left(\mathrm{~m}^{2} \mathrm{~s}\right)^{-1}\right]$, the difference between 


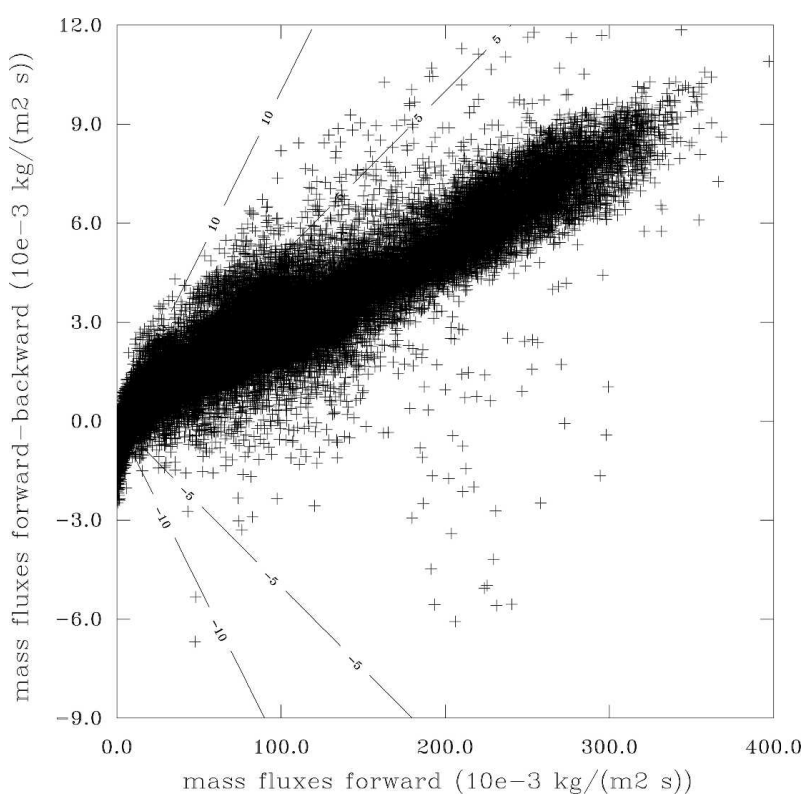

FIG. 3. Scatterplot of the monthly mean upward mass fluxes $\left(10^{-3} \mathrm{~kg} \mathrm{~m}^{-2} \mathrm{~s}^{-1}\right)$ in each grid column summed up over all model levels. The fluxes from the forward simulations are plotted against the difference between the fluxes from the forward simulation and the backward simulation. The labeled lines illustrate the difference (\%) between forward and backward mass fluxes relative to the forward mass fluxes.

forward and backward mass fluxes is mostly below

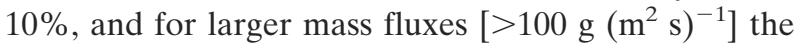
difference is below $5 \%$. The relative deviation averaged over all grid points is $2.84 \%$ with a bias of $2.78 \%$. Similar results were found for single model levels as well as for the comparison of the forward and backward mass fluxes at distinct times. If the FLEXPART time step is reduced, the relative deviation and the bias are smaller. For instance, with a FLEXPART time step of $300 \mathrm{~s}$, both the relative deviation and the bias are below $1 \%$. We conclude from these results that the error introduced by the unphysical calculation of $M_{\mathrm{cb}}$ in the backward mode is minor and can be tolerated given the large overall uncertainties of convective parameterizations. Figure 3 indicates that the backward mass fluxes are systematically too low. This is due to the fact that convection tends to stabilize the atmosphere and hence to reduce the convective mass fluxes in the course of time. Thus, in the backward mode, when the somewhat lower $M_{\mathrm{cb}}(t+1)$ is used to calculate the redistribution matrix $M_{i, j}(t)$, the intensity of the convection is underestimated and results in somewhat lower mass fluxes.

\section{Mass fluxes and convective precipitation}

The convective precipitation rates and mass fluxes diagnosed offline from the EZ99 scheme were com- pared with those archived online in the ERA-40 data. ERA-40 used the scheme by Tiedtke (1989, hereinafter called the ECMWF scheme; see also Tiedtke 1993; Nordeng 1994; Gregory et al. 2000), which is based on theory 1 as described in the introduction. Onlinearchived and offline-diagnosed mass fluxes can differ from each other even if the same type of convection scheme is used (Olivié et al. 2004), but we would at least like to see similar magnitudes and spatial patterns when comparing the results from the two convection schemes.

Figures 4a and 4b show the ECMWF and the EZ99 convective upward mass fluxes, respectively, summed up over all vertical layers and averaged over 1 month. Their differences are displayed in Fig. 4c. This figure and the following ones refer to October 1983 (ERA-40 data) as an example. We performed such comparisons also for other months, during winter and summer, and came to similar results concerning the differences. The archived ECMWF convective upward mass fluxes are larger than those produced offline by the EZ99 scheme over land areas and especially over marine areas in Southeast Asia, Central America, and the middle and high latitudes (Fig. 4c). In contrast, the EZ99 scheme shows larger mass fluxes north and south of the intertropical convergence zone. In general, the maxima in the EZ99 scheme are not as pronounced as those in the ECMWF scheme, especially in the eastern and western tropical Pacific Ocean. The EZ99 scheme produces the largest mass fluxes over the central Pacific, and the highest values from the ECMWF scheme can be found over Southeast Asia. In the global mean the mass fluxes of the EZ99 scheme were found to be lower than those of the ECMWF scheme by about $26 \%$. Vertical sections of the mean zonal upward convective mass fluxes from the EZ99 scheme and the ECMWF scheme, as well as the difference between them, are shown in Fig. 5. In the middle and upper troposphere north and south of the intertropical convergence zone, as well as close to the ground, the EZ99 scheme produces higher mass fluxes than the ECMWF scheme. In all other regions, the opposite is the case. The large differences at low levels are most likely due to the different assumptions on the conditions for triggering convection in the two schemes. Whereas in the ECMWF scheme the occurrence of convection is based on the supply of moisture by the large-scale convergence and boundary layer turbulence, convection in the EZ99 scheme depends only on temperature and humidity profiles near the surface.

Results similar to those of the upward convective mass fluxes in Fig. 4 were found for the convective precipitation patterns (Fig. 6). Although there are regions in southern Africa, South America, and Tibet 
(a) MONTHLY MEAN FOR 198310 EZ99 SCHEME

(a) MINIMUM VaLuE: $0.000 \mathrm{E}+00$ MaXimum Value: $0.555 \mathrm{E}+00$ MEAN VAlUE: $0.110 \mathrm{E}+00$

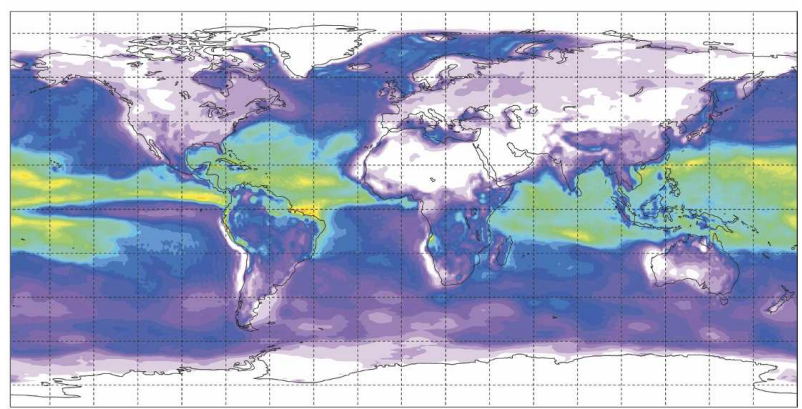

(b) MONTHLY MEAN FOR 198310 ECMWF SCHEME

b) Minimum Value: $0.000 \mathrm{E}+00$ MaXimum Valde: $0.610 \mathrm{E}+00$ MEAN VALUE: $0.149 \mathrm{E}+00$

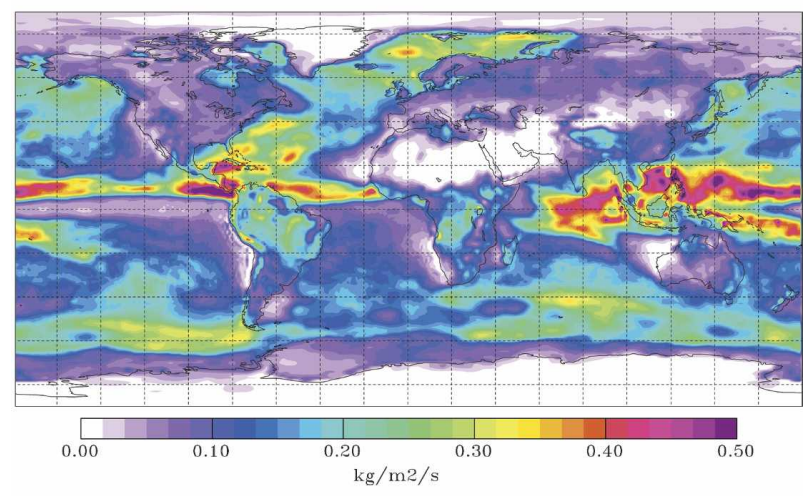

(c) MONTHLY MEAN FOR 198310 ECMWF - EZ99 SCHEME

MINIMUM VALUE: $-0.534 \mathrm{E}+00$ MAXIMUM VALUE: $0.404 \mathrm{E}+00$ MEAN VALUE: $0.393 \mathrm{E}-0$

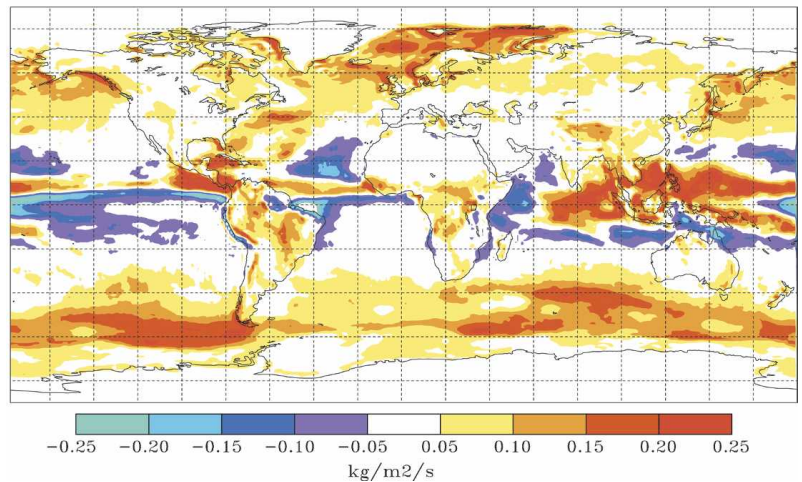

FIG. 4. Monthly mean (October 1983) upward convective mass fluxes $\left(\mathrm{kg} \mathrm{m}^{-2} \mathrm{~s}^{-1}\right)$ summed up over all levels from (a) the EZ99 scheme, (b) the ECMWF scheme, and (c) the difference between them.

where the EZ99 scheme produces more convective precipitation, the global mean in the EZ99 scheme is only $76 \%$ of that produced by the ECMWF scheme. We interpret this result as positive, because previous studies have shown that precipitation is overestimated in the ECMWF model. This is especially the case in the intertropical convergence zone where the ECMWF model shows nearly 2 times as much precipitation as that from observations from the Global Precipitation (a) $\quad$ EZ99 SCHEME

MINIMUM VALUE: $0.000 \mathrm{E}+00$ MAXIMUM VALUE: $0.916 \mathrm{E}+01$ MEAN VALUE: $0.321 \mathrm{E}+00$

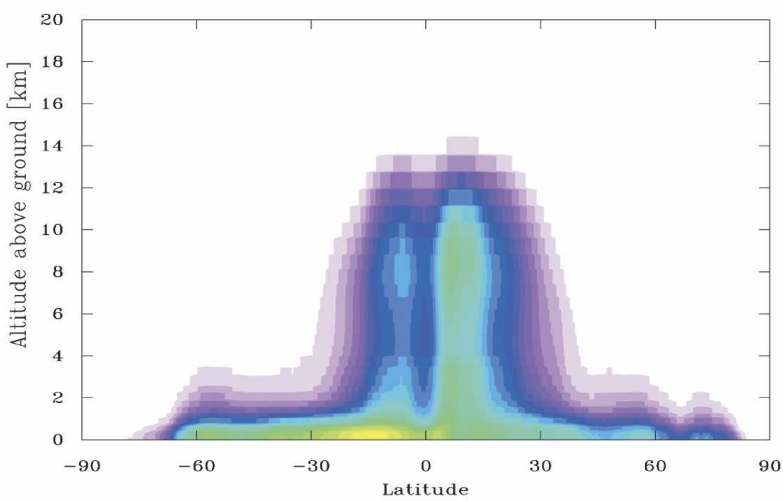

(b)

ECMWF SCHEME

MINIMUM Value: $0.000 \mathrm{E}+00$ MaXIMUM Value: $0.277 \mathrm{E}+02$ MEAN Value: $0.517 \mathrm{E}+00$

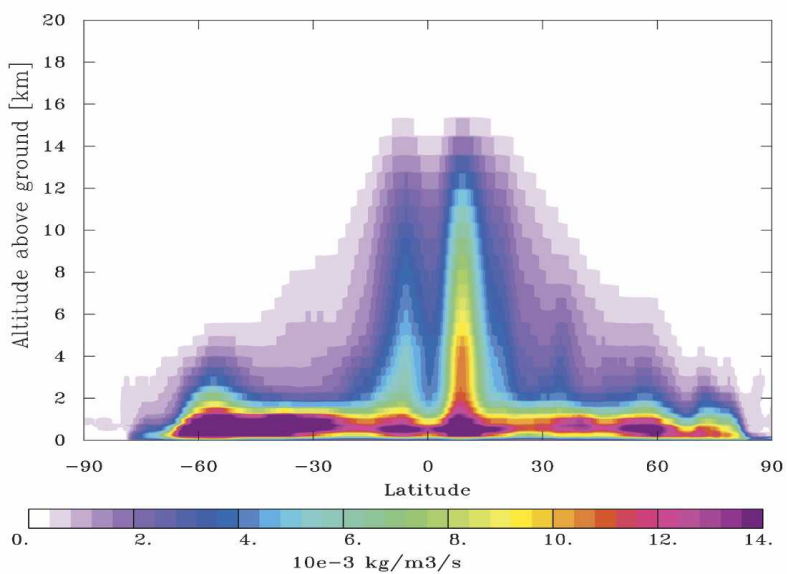

(c) ECMWF - EZ99 SCHEME MEAN FOR 198310

Minimum Value: $-0.767 \mathrm{E}+01$ MAXimum Value: $0.214 \mathrm{E}+02$ MEAN Value: $0.196 \mathrm{E}+00$

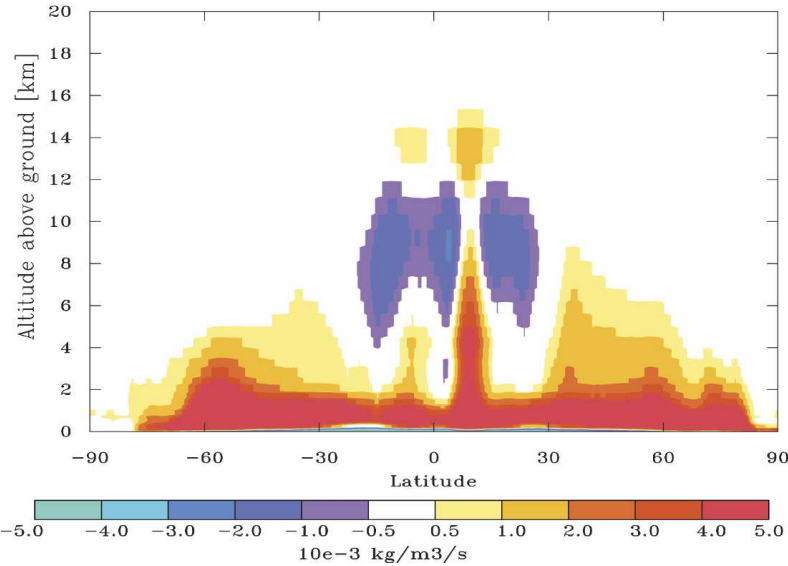

FIG. 5. Monthly mean (October 1983) vertical sections of the zonal mean of the upward convective mass fluxes $\left(10^{-3} \mathrm{~kg} \mathrm{~m}^{-3}\right.$ $\mathrm{s}^{-1}$ ) from (a) the EZ99 scheme, (b) the ECMWF scheme, and (c) the difference between them. 
(a) CONVECTIVE PRECIPITATION FROM EZ99 SCHEME

Minimum value: $0.000 \mathrm{E}+00$ MaXIMUM VAlUE: $0.103 \mathrm{E}+02$ MEan Value: $0.786 \mathrm{E}+00$

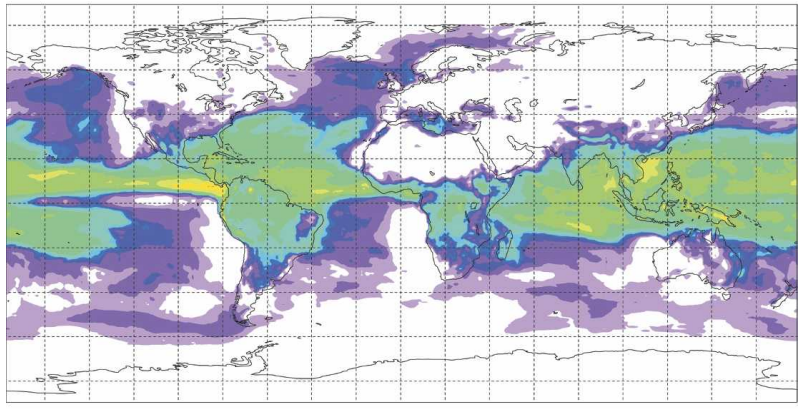

(b)

CONVECTIVE PRECIPITATION FROM ECMWF SCHEME MONTHLY MEAN FOR 198310

MiNimuM Value: $0.000 \mathrm{E}+00$ MaXimum Value: $0.205 \mathrm{E}+02$ MEAN VALUE: $0.104 \mathrm{E}+01$
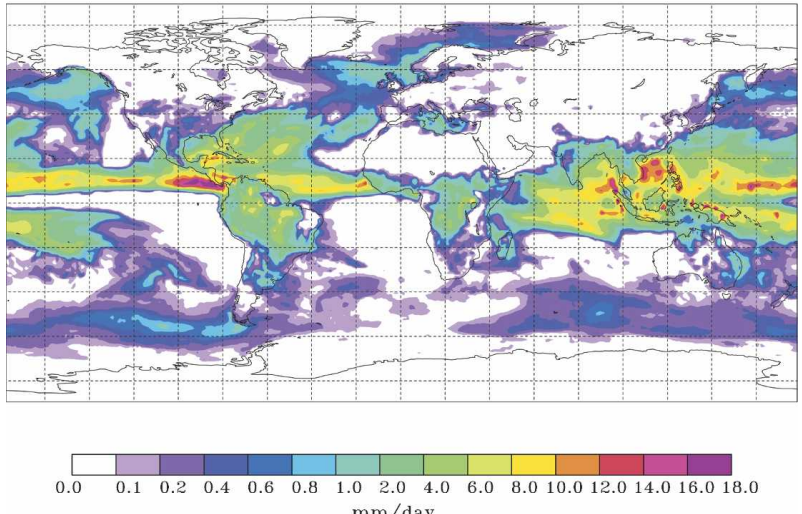
$\mathrm{mm} /$ day (c) DIFFERENCE ECMWF-EZ99 CONVECTIVE PRECIPITATION
MONTHLY MEAN FOR 198310

Minimum Value: $-0.854 \mathrm{E}+01$ MaXimum VaLUE: $0.153 \mathrm{E}+02$ MeAN ValuE: $0.253 \mathrm{E}+00$
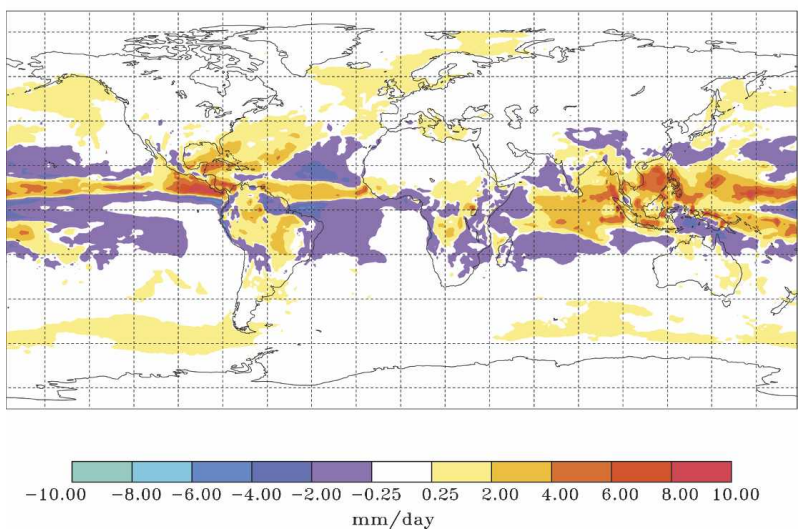

FIG. 6. Monthly mean (October 1983) convective precipitation rates $\left(\mathrm{mm} \mathrm{day}^{-1}\right)$ from (a) the EZ99 scheme, (b) the ECMWF scheme, and (c) the difference between them.

Climatology Project (GPCP) - a feature that appears to be linked to the ECMWF convection scheme (Stohl and James 2004). If convective precipitation is combined with the archived large-scale precipitation from ERA-40 (Figs. 7a,b), our results can be compared with the observation-based analyses from GPCP (Fig. 7c).
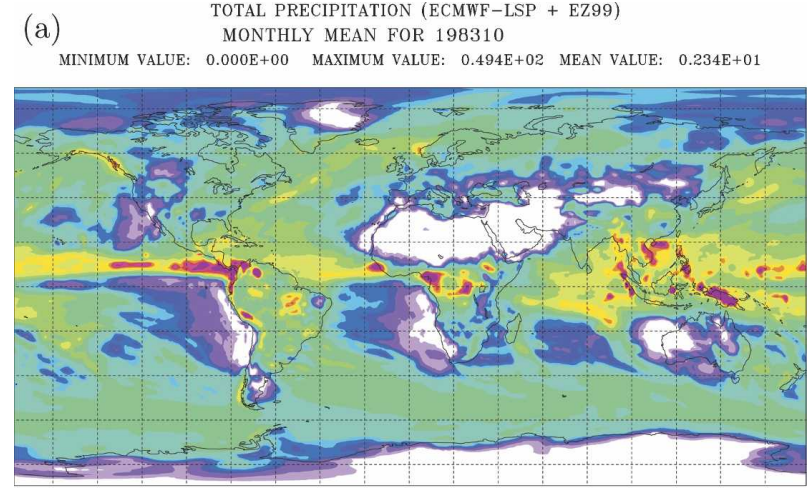

TOTAL PRECIPITATION (ECMWF-LSP + ECMWF-CP) MONTHLY MEAN FOR 198310

Minimum Value: $0.000 \mathrm{E}+00$ MaXimum Value: $0.560 \mathrm{E}+02$ MEAN VALUE: $0.259 \mathrm{E}+0$

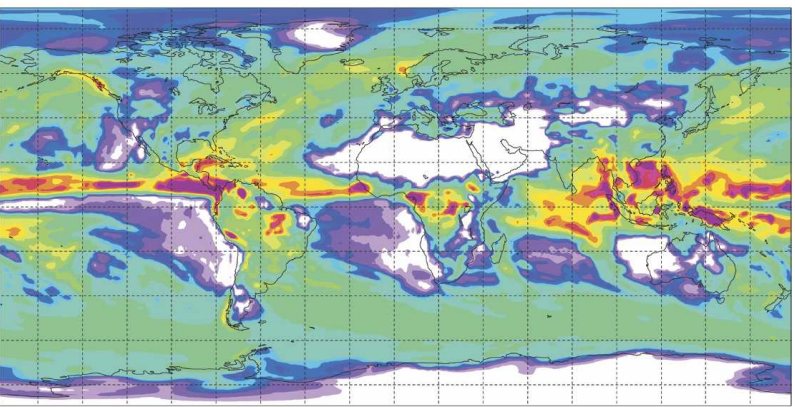

OBSERVED PRECIPITATION FROM GPCP

(c) MONTHLY MEAN FOR 198310

Mivimum Value: $0.000 \mathrm{E}+00$ MaXimum Value: $0.181 \mathrm{E}+02$ MEAN Value: $0.233 \mathrm{E}+01$
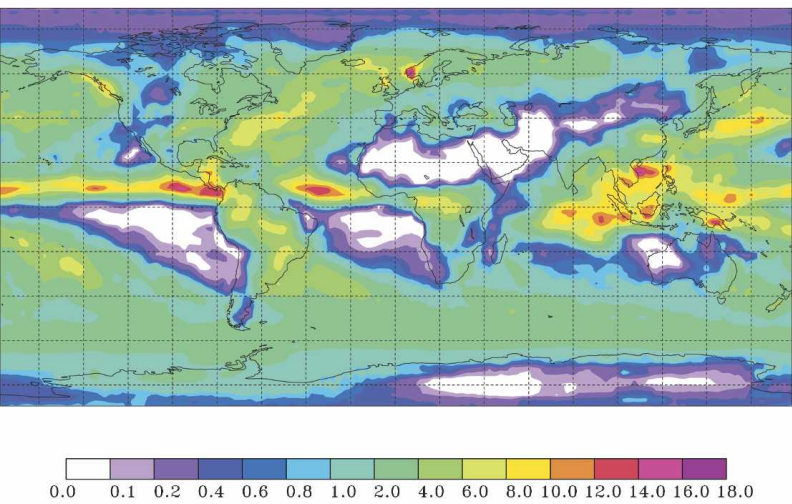

$\mathrm{mm} /$ day

FIG. 7. Monthly mean (October 1983) total precipitation rates $\left(\mathrm{mm} \mathrm{day}{ }^{-1}\right)$ calculated from (a) the convective precipitation from the EZ99 scheme plus the large-scale precipitation from the ECMWF model and (b) the convective precipitation from the ECMWF scheme plus the large-scale precipitation from the ECMWF model. (c) The observed precipitation rate from GPCP.

Two features are prominent from the comparison: first, the model results are dominated by the large-scale precipitation, and second the model overestimates total precipitation, especially over marine areas in Southeast Asia, and over parts of Africa, Central America, and the tropical Pacific at around $10^{\circ} \mathrm{N}$. Some of the modeled precipitation maxima fit the observations better if 
the convective precipitation is taken from the EZ99 scheme, for instance, over the tropical Pacific at around $10^{\circ} \mathrm{N}$ and over Southeast Asia. In addition, the global mean precipitation rate from the EZ99 scheme in combination with large-scale ECMWF precipitation (2.34 $\mathrm{mm}$ day $\left.^{-1}\right)$ is closer to the observed one $(2.33 \mathrm{~mm}$ day $^{-1}$ ) than the total precipitation from the ECMWF model $\left(2.59 \mathrm{~mm} \mathrm{day}^{-1}\right)$. This positive result is not sufficient to conclude that the EZ99 scheme produces better results than the ECMWF scheme, but it shows that the EZ99 scheme gives acceptable results with our implementation in FLEXPART.

\section{Comparison with measurement data from tracer studies}

Tracer experiment data provide unique opportunities to test long-range dispersion models, because the amount of the released tracer is known and the measurements can be quantitatively compared with the model results. Here, we use tracer experiment data to evaluate the convection scheme in the FLEXPART model. We performed model runs with convection switched on and off and compared them with the measurement data.

Considerable differences between model runs with and without convection are expected mainly above the atmospheric boundary layer (ABL). It is therefore desirable to have measurements available not only at the surface, but also at higher levels-for example, from aircraft. To the knowledge of the authors, the only aircraft data available from large-scale tracer experiments were those from the Cross-Appalachian Tracer Experiment (CAPTEX) (Ferber et al. 1986) and the Across North America Tracer Experiment (ANATEX) (Draxler et al. 1991). However, these experiments took place in the midlatitudes in autumn and winter, respectively, a period during which convection is weak there, and experiments in the Tropics (where convection is most important) do not exist. During ANATEX, for instance, the tracer was released frequently into strong surface inversions (Stunder and Draxler 1989). In addition, only few CAPTEX and hardly any ANATEX aircraft measurements are available above the ABL. The ANATEX aircraft measurements were used to provide the initial tracer path and distribution and were thought to complement the sparse surface network in the vicinity of the release location (Stunder and Draxler 1989). During CAPTEX at least two cases in which the tracer plume passed a convective region, aircraft measurements above the ABL were available, and differences between model runs with and without convection could be assessed could be identified from a visual in- spection. However, no such cases could be found during ANATEX. Either there were no ANATEX measurements available at altitudes at which the model runs with and without convection showed differences or ANATEX measurements were available but the model runs with and without convection showed no or only very small differences. An analysis of whether the convection scheme brings an improvement was therefore difficult using the tracer experiment data. However, we will present the two case studies from CAPTEX, and for both CAPTEX and ANATEX we present statistical performance parameters that are widely used for model validation. These are the Pearson correlation coefficient $r$, the normalized mean square error $E=(1 /$ N) $\sum_{i=1}^{N}\left(P_{i}-M_{i}\right)^{2} /(\overline{P M})$, and the fractional bias $F=$ $2 B /(\bar{P}+\bar{M})$, where $B=(1 / N) \sum_{i=1}^{N}\left(P_{i}-M_{i}\right)$ is the bias, $N$ is the number of paired data points, $P_{i}$ and $M_{i}$ are the model predictions and measurements, respectively, and $\bar{P}$ and $\bar{M}$ are the average predictions and measurements, respectively.

Note that a validation of the previous FLEXPART, version 2.0, with CAPTEX and ANATEX data has already been performed by Stohl et al. (1998), but they used surface measurements only and their simulations were based on ECMWF operational data whereas here ERA-40 data are used. In addition, FLEXPART, version 2.0, was not equipped with a convection scheme.

\section{a. CAPTEX}

The CAPTEX experiment took place in September/ October 1983. Seven 3-h releases of approximately 200 $\mathrm{kg}$ of perfluoromonomethylcyclohexane $(\mathrm{PMCH})$ were made from Dayton, Ohio (DAY), and Sudbury, Ontario (SUD). Tracer samples were collected at 84 surface sites covering the northeastern United States and southeastern Canada. In addition, seven aircraft were operated. The aircraft generally flew at constant altitudes above mean sea level (MSL). In a typical case, several aircraft, stacked vertically, flew back and forth laterally across the predicted plume location. Data are generally available until $36-48 \mathrm{~h}$ after the release and up to distances of about $1000 \mathrm{~km}$ away from the release location. Data from release 6 are not presented here, because only a few samples were collected at the surface and no aircraft data are available for this release.

For each of the six remaining releases we simulated 250000 particles carrying the released mass of $\mathrm{PMCH}$. Figure 8 shows a comparison between the surface measurements and the model results with the convection scheme switched on. The small-scale variations of the plumes are not captured by the model because they are mostly below the resolution of the meteorological input data, but the overall location of the plumes is simulated 
(a)

RELEASE 1

Simulation start 19830918130000 Actual time 19830919130000

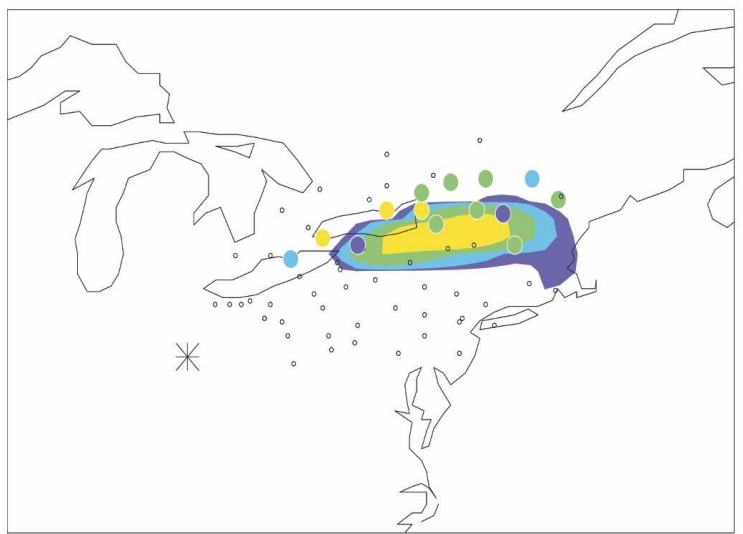

(c)

RELEASE 3

Simulation start 19831002180000 Actual time 19831004

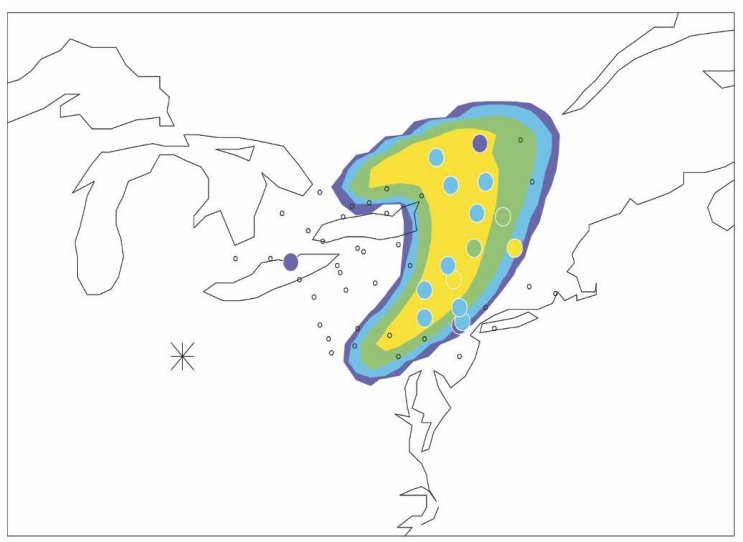

(e)

RELEASE 5

Simulation start 1983102620000 Actual time 19831026200000
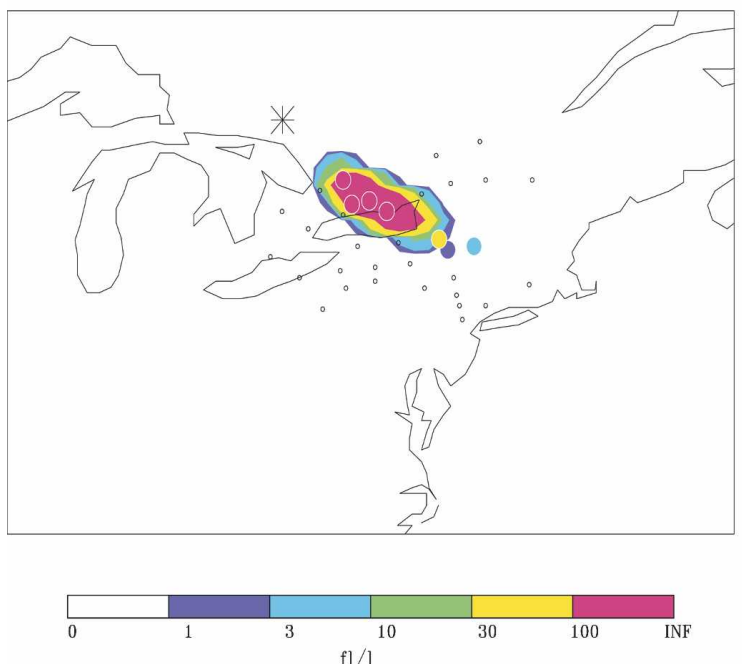

(b)

RELEASE 2

Simulation start 19830925150000 Actual time 19830926210000

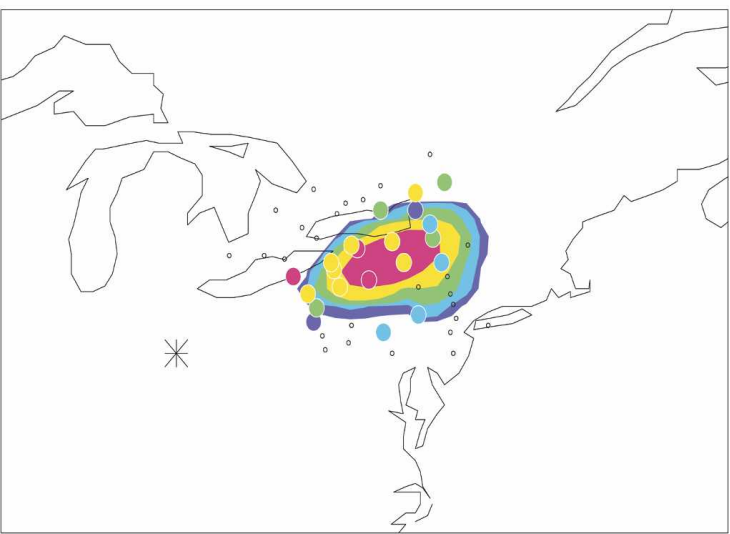

(d)

RELEASE 4

Simulation start 19831014150000 Actual time 1983101590000

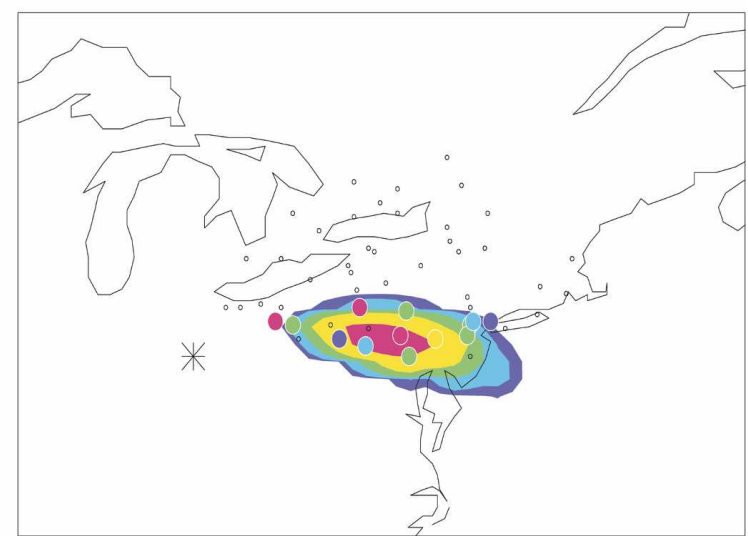

(f)

RELEASE 7

Simulation start 1983102910000 Actual time 1983103010000
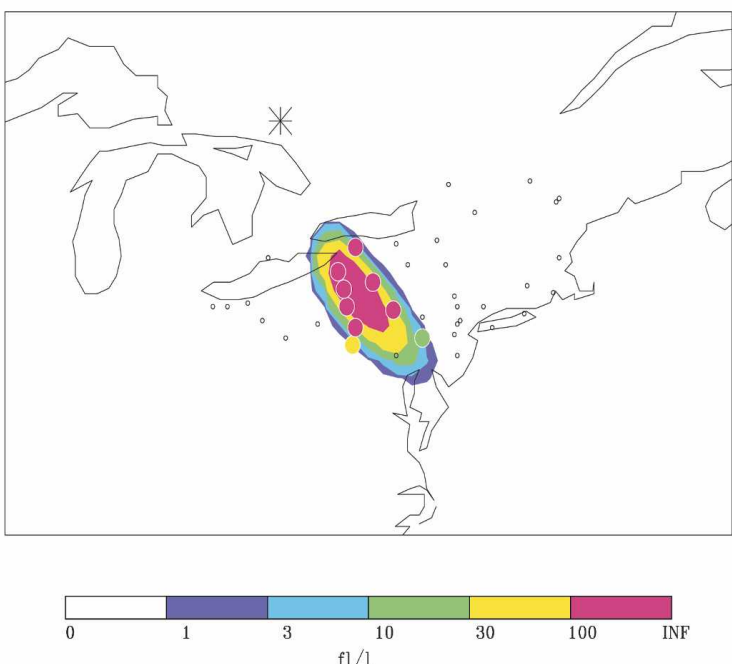

FIG. 8. Surface FLEXPART PMCH tracer concentrations (colored contours) and surface observations (colored dots) (fL $\mathrm{L}^{-1}$ ) during CAPTEX for (a) release 1 after $24 \mathrm{~h}$, (b) release 2 after $30 \mathrm{~h}$, (c) release 3 after $30 \mathrm{~h}$, (d) release 4 after $18 \mathrm{~h}$, (e) release 5 after $18 \mathrm{~h}$, and (f) release 7 after $24 \mathrm{~h}$. Measurements with zero concentration are indicated as small black circles. The release locations are marked with asterisks. 
TABLE 2. Analysis of model results against surface measurements during CAPTEX; $N$ indicates the number of data points. All coefficients $r$ are significantly positive on a confidence level of $99 \%$. Conv and noconv are defined in the text.

\begin{tabular}{|c|c|c|c|c|c|c|c|}
\hline \multirow[b]{2}{*}{ Release } & \multirow[b]{2}{*}{$N$} & \multicolumn{3}{|c|}{ Conv } & \multicolumn{3}{|c|}{ Noconv } \\
\hline & & $r$ & $E$ & $F$ & $r$ & $E$ & $F$ \\
\hline 1 & 362 & 0.24 & 100.22 & -0.70 & 0.23 & 100.27 & -0.70 \\
\hline 2 & 366 & 0.32 & 28.17 & -0.41 & 0.32 & 28.67 & -0.42 \\
\hline 3 & 366 & 0.47 & 37.48 & 0.93 & 0.47 & 37.43 & 0.93 \\
\hline 4 & 312 & 0.60 & 72.40 & -0.86 & 0.60 & 72.02 & -0.86 \\
\hline 5 & 316 & 0.81 & 12.57 & 0.12 & 0.81 & 12.78 & 0.09 \\
\hline 7 & 202 & 0.65 & 14.64 & -0.69 & 0.65 & 14.93 & -0.70 \\
\hline All & 1924 & 0.46 & 33.03 & -0.25 & 0.46 & 33.42 & -0.26 \\
\hline
\end{tabular}

well in releases $2-5$ and 7 . For release 1 , the model plume was transported slightly too far south relative to the measurements, and for release 3 the plume maximum is overestimated by the model. Table 2 summarizes $r, E$, and $F$ for the model runs with (conv) and without (noconv) convection for all releases. There is hardly any difference between the runs with and without convection. The correlation $r$ and error $E$ for release 5 are high; those for release 1 are the lowest. For releases $1,2,4$, and 7 there is a negative $F$, whereas for release 3 the model strongly overestimates the tracer concentrations. Release 5 has only a slight positive bias. Note that the statistical numbers found here differ from those found in Stohl et al. (1998) because of the use of different meteorological datasets and model updates.

Because no substantial differences between the model runs with and without convection were found at the surface, we examined results at higher levels and concentrate on those flights that took measurements not only in the ABL but also above the ABL. Table 3 summarizes the statistical results for these flights. The correlations $r$ for two flights after release 2 and the flight after release 4 are high. For the flight after release 5 the results for $r, E$, and $F$ are worst. During this flight, the aircraft flew several profiles between 1 - and $3-\mathrm{km}$ altitudes. A careful examination revealed that at higher levels the modeled plume captured the measurements very well but that at lower levels it was somewhat too slow, leading to the bad values reported in Table 3.

By comparing the values with and without convection in Table 3 , it is evident that, except for release 3 , the model runs with convection yield better correlation coefficients $r$ and mostly better $E$ and $F$ values than without convection. An examination of the meteorological conditions during the different releases showed that only during releases 2 and 5 did the plume travel through a region with convective activity, and differences between the runs with and without convection could also be assessed from a visual inspection of the
TABLE 3. Analysis of model results against aircraft measurements from selected flights during CAPTEX; $N$ indicates the number of data points. All coefficients $r$ are significantly positive on a confidence level of $95 \%$.

\begin{tabular}{|c|c|c|c|c|c|c|c|c|}
\hline \multirow[b]{2}{*}{ Release } & \multirow[b]{2}{*}{$N$} & \multirow[b]{2}{*}{ Aircraft } & \multicolumn{3}{|c|}{ Conv } & \multicolumn{3}{|c|}{ Noconv } \\
\hline & & & $r$ & $E$ & $F$ & $r$ & $E$ & $F$ \\
\hline 2 & 24 & 1 & 0.37 & 1.92 & 0.79 & 0.35 & 1.95 & 0.79 \\
\hline 2 & 27 & 2 & 0.54 & 2.29 & 0.71 & 0.52 & 2.61 & 0.73 \\
\hline 2 & 17 & 3 & 0.61 & 1.97 & -0.28 & 0.58 & 2.23 & -0.32 \\
\hline 3 & 29 & 5 & 0.47 & 6.50 & -0.90 & 0.47 & 6.44 & -0.90 \\
\hline 4 & 7 & 4 & 0.61 & 0.47 & 0.39 & 0.58 & 0.48 & 0.37 \\
\hline 5 & 33 & 5 & 0.30 & 23.61 & -1.48 & 0.28 & 21.99 & -1.45 \\
\hline
\end{tabular}

results. Release 2 took place near DAY during daytime under anticyclonic conditions. The plume traveled northeastward over a convective region $36 \mathrm{~h}$ after the release. Release 5 took place in SUD during nighttime after a frontal passage. The plume was partly lifted by convection about $12 \mathrm{~h}$ after the release. Figure 9 compares aircraft measurements with model results with (Fig. 9, left panels) and without (Fig. 9, right panels) convection at different altitudes for releases 2 and 5 . Cross sections along the black lines indicated in Figs. 9a and 9c highlight the vertical plume structures (Fig. 10) along the flight tracks. Although the model still underestimates the measurements at higher altitudes, the agreement between measurements and model is better in all cases with the convection scheme switched on. Especially for release 5, the location and the values of the plume are closer to the measurements if convection is accounted for. Note in this case that at 3-km altitude the model does not even show concentrations in the case without convection, although the measurements indicate high tracer values there. No aircraft measurements above $3 \mathrm{~km}$ were made during the whole CAPTEX period.

\section{b. ANATEX}

During ANATEX, 33 releases of different perfluorocarbons were made from each of two sites between 5 January 1987 and 29 March 1987. Every 60 h, alternating between daytime and nighttime, the tracers were released in a 3-h period. Ortho-cis-perfluorodimethylcyclohexane (ocPDCH) was released from St. Cloud (STC), Minnesota, and perfluorotrimethylcyclohexane (PTCH) was released from Glasgow (GGW), Montana. Surface measurements were taken at 77 sites in the eastern part of the United States and southeastern Canada, with a low spatial and temporal resolution relative to the CAPTEX experiment. In addition, during most of the releases aircraft measurements were performed within a range of at most $450 \mathrm{~km}$ from STC 


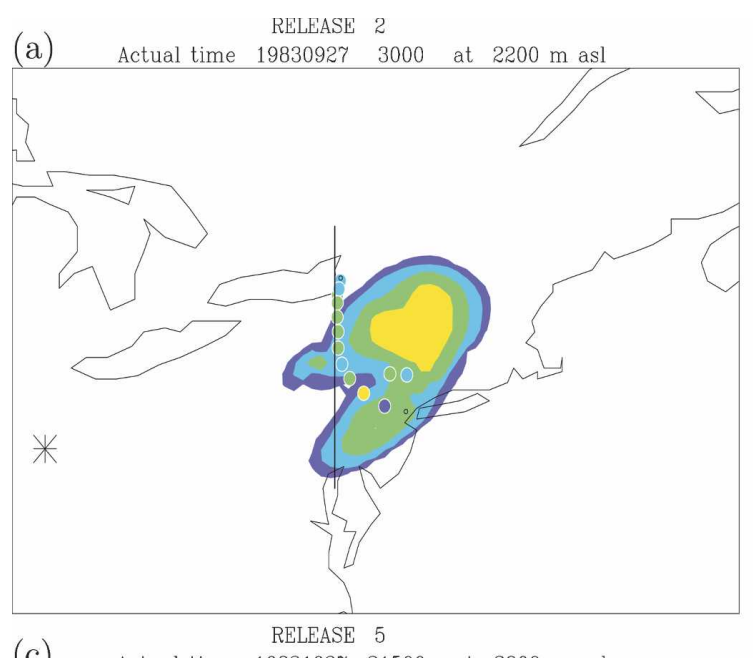

RELEASE 5
(c) Actual time $19831027 \quad 21500$ at $2800 \mathrm{~m}$ asl
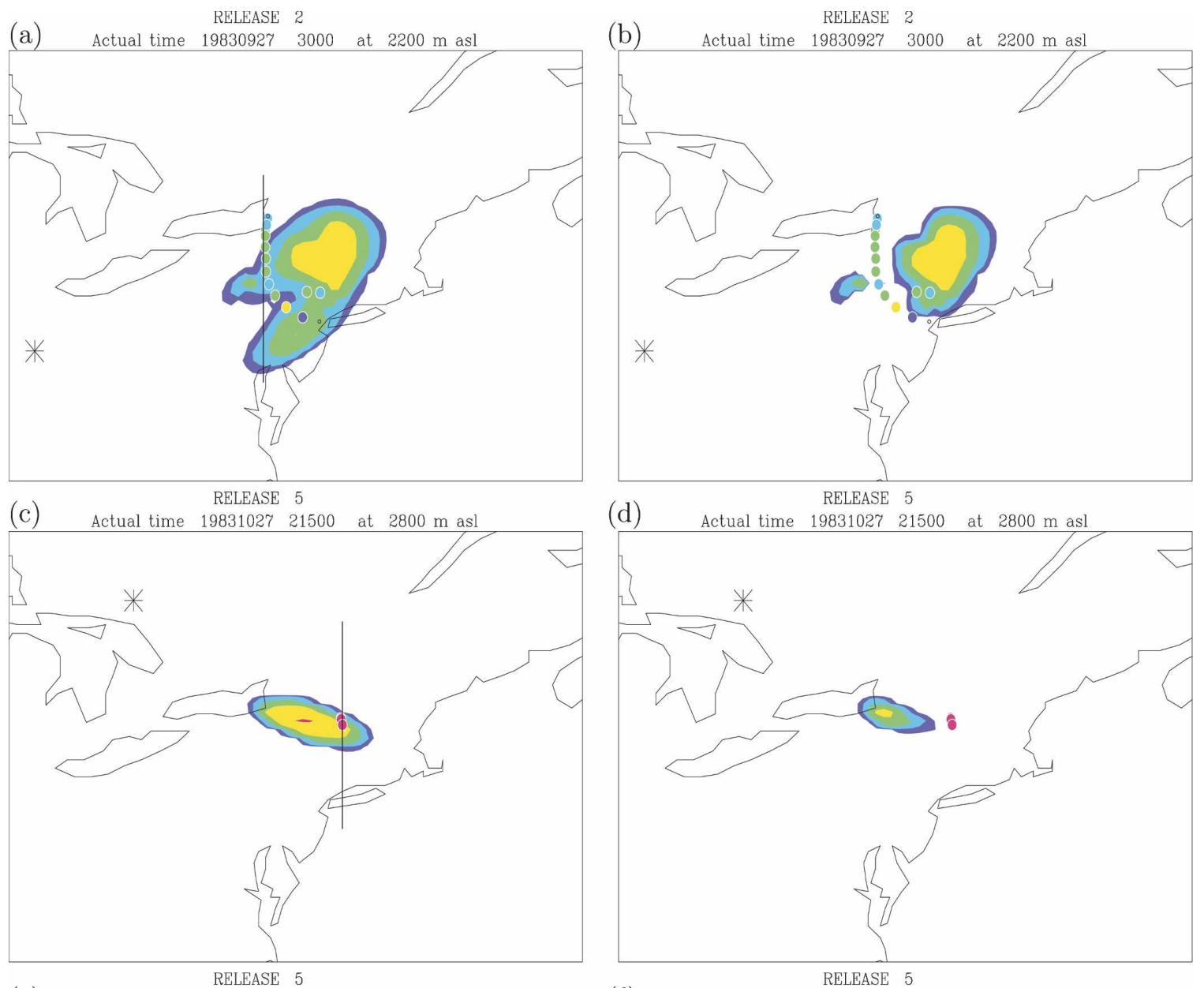

(e) Actual time $19831027 \quad 21500$ at $3000 \mathrm{~m}$ asl
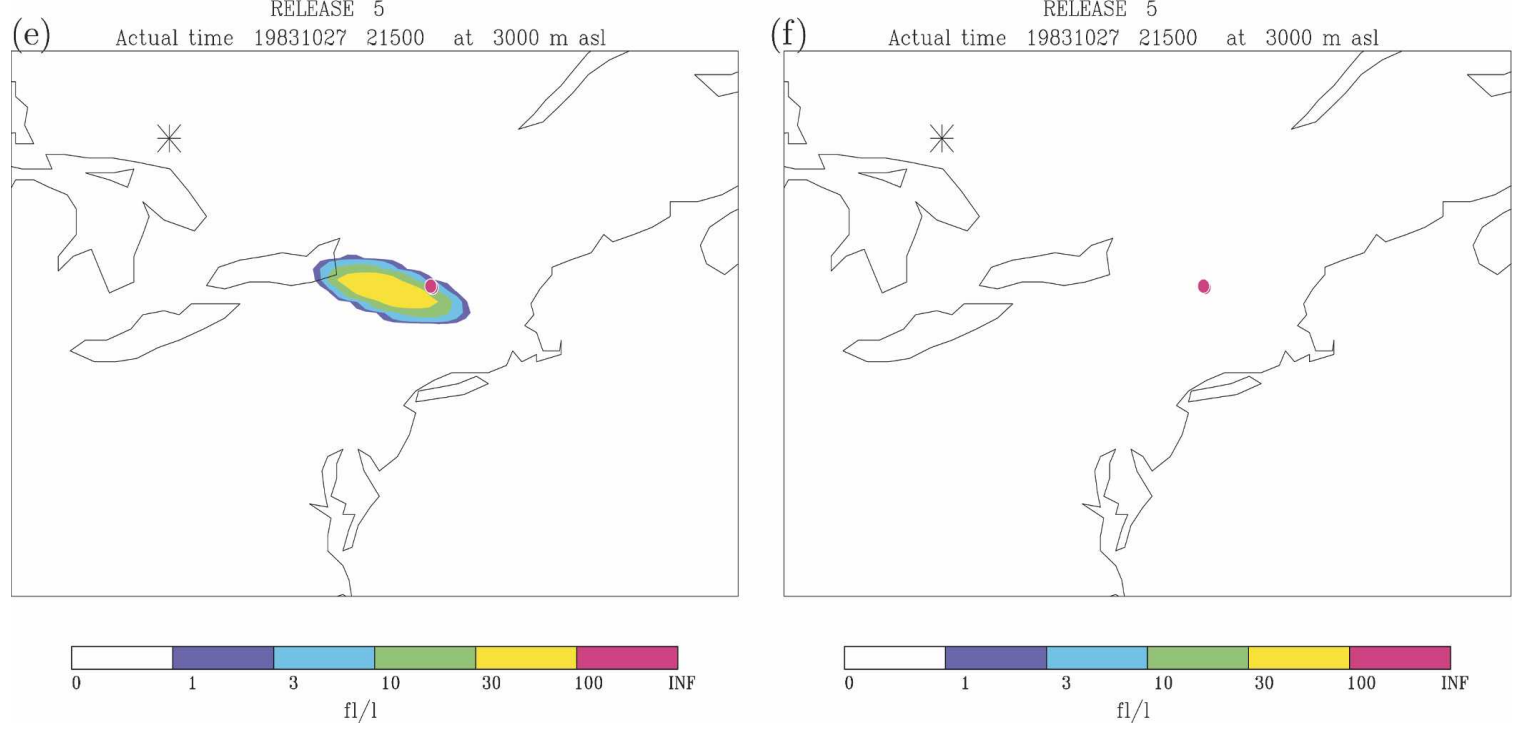

FIG. 9. FLEXPART PMCH tracer concentrations (colored contours) and aircraft observations (colored dots) (fL $\mathrm{L}^{-1}$ ) during CAPTEX (left) with and (right) without convection for (a), (b) release 2 at 2200-m altitude above sea level after 36 h, (c), (d) release 5 at 2800-m altitude above sea level after 24 h, and (e), (f) release 5 at 3000-m altitude above sea level after 24 h. The black lines in (a) and (c) indicate the location of the vertical sections shown in Fig. 10. Measurements with zero concentration are indicated as small black circles. The release locations are marked with asterisks. 
(a)

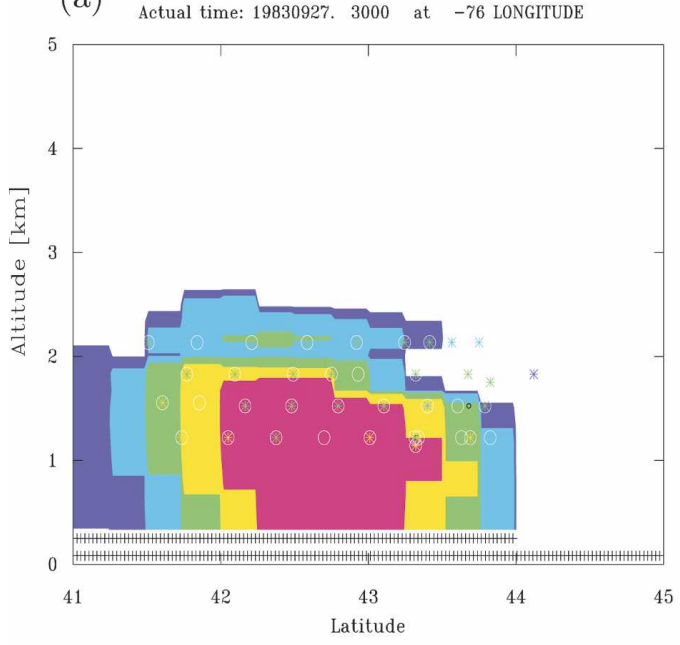

(c) RELEASE 5

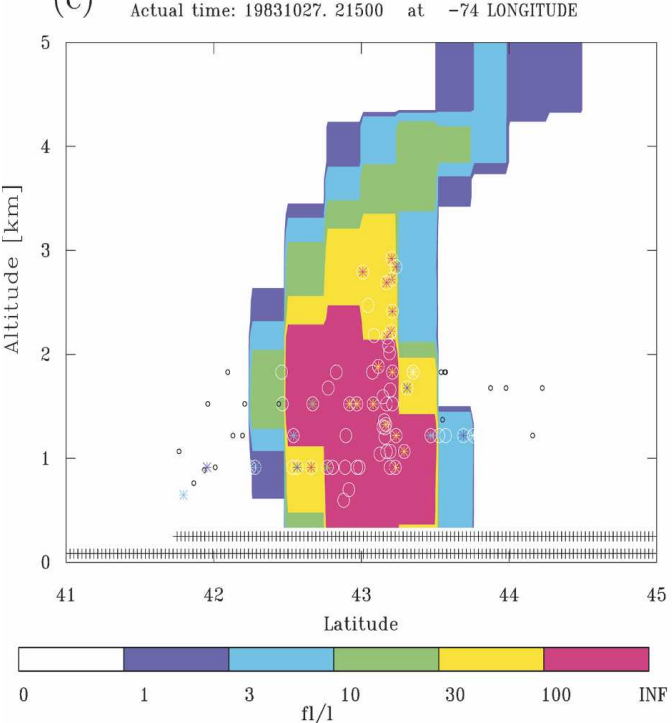

(b) RELEASE 2

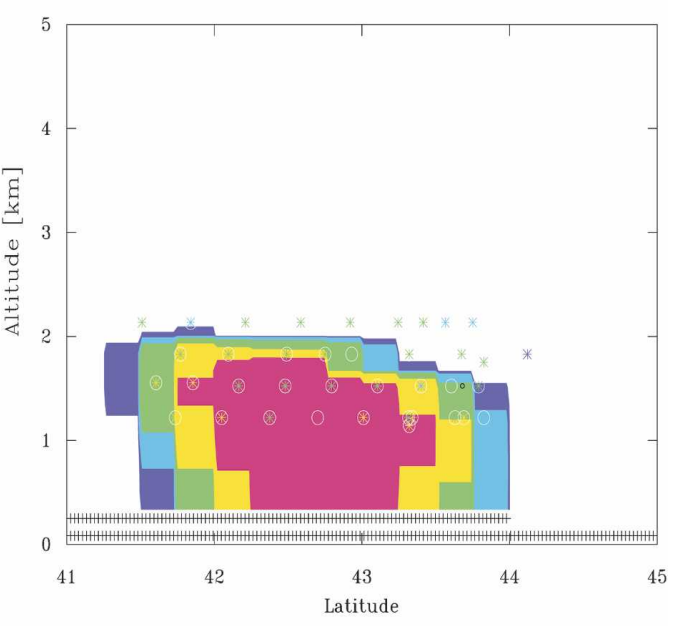

(d) RELFASE 5

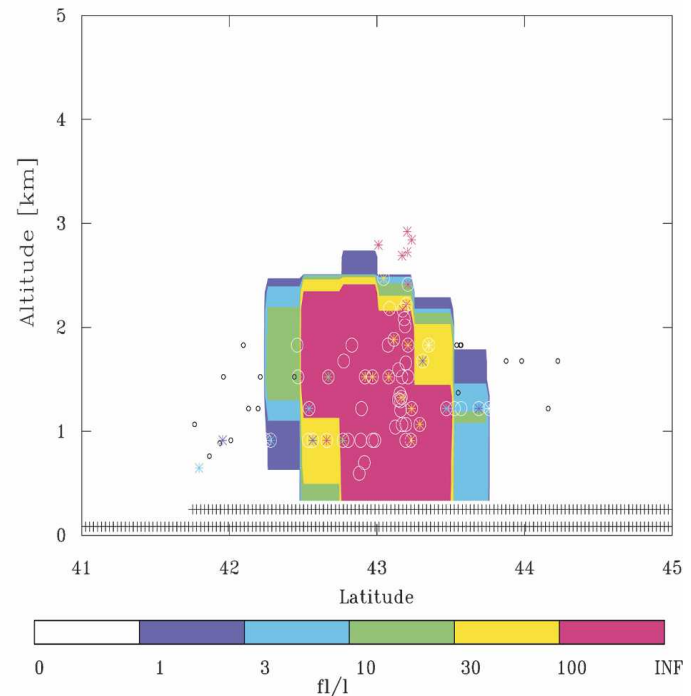

FIG. 10. Vertical section along the black lines indicated in Figs. 9a,c (left) with and (right) without convection for (a), (b) release 2 and (c), (d) release 5. The times are the same as in Fig. 9. Colored contours are the FLEXPART $\mathrm{PMCH}$ tracer concentrations ( $\mathrm{fL} \mathrm{L}^{-1}$ ), and colored stars underlined with white circles are the aircraft measurements $\left(\mathrm{fL} \mathrm{L} \mathrm{L}^{-1}\right)$. Measurements with zero concentration are indicated as small black circles. Gray-shaded areas indicate the orography.

and GGW (Stunder and Draxler 1989), respectively. While one aircraft was operated near STC, two aircraft mostly flying one over the other were operated near GGW. Unfortunately, even fewer measurements above the ABL than during CAPTEX were performed. The aircraft flew mostly below $1.5 \mathrm{~km}$. Profiles up to $1.9 \mathrm{~km}$ were flown after three releases from GGW, and the maximum flight altitude for releases from STC was about $3 \mathrm{~km}$, but this height was covered only in two vertical profiles.

Similar to CAPTEX we simulated 250000 particles carrying the released tracer mass of ocPDCH or PTCH, respectively, for each release. From a visual inspection, we could not identify cases showing differences between the runs with and without convection and for which aircraft measurements were available at the same time. In addition, the measurements above the ABL were too few to separate those flights with measurements above the ABL from the other flights and to perform a statistical analysis for them. Therefore, we performed a global analysis of the model results against aircraft measurements from all flights for each release (Table 4 and Table 5). The normalized mean square error $E$ shows outstanding bad values for ocPDCH 18 
TABLE 4. Analysis of model results against aircraft measurements from all flights for the ocPDCH releases at STC during ANATEX; $N$ indicates the number of data points. Coefficients $r$ that are significantly positive on a confidence level of $95 \%$ are indicated by an asterisk.

\begin{tabular}{|c|c|c|c|c|c|c|c|}
\hline \multirow[b]{2}{*}{ Release } & \multirow[b]{2}{*}{$N$} & \multicolumn{3}{|c|}{ Conv } & \multicolumn{3}{|c|}{ Noconv } \\
\hline & & $r$ & $E$ & $F$ & $r$ & $E$ & $F$ \\
\hline ocPDCH 4 & 34 & -0.10 & 21.88 & -0.96 & -0.10 & 21.87 & -0.96 \\
\hline ocPDCH 5 & 27 & $0.46^{*}$ & 24.67 & 0.61 & $0.47 *$ & 24.54 & 0.61 \\
\hline ocPDCH 6 & 27 & -0.16 & 30.43 & -1.70 & -0.16 & 28.74 & -1.68 \\
\hline ocPDCH 7 & 18 & $0.58 *$ & 12.40 & -0.98 & $0.58 *$ & 11.69 & -0.96 \\
\hline ocPDCH 8 & 19 & -0.16 & 72.44 & 1.81 & -0.16 & 72.48 & 1.81 \\
\hline ocPDCH 10 & 15 & 0.09 & 44.33 & 1.14 & 0.08 & 45.09 & 1.15 \\
\hline ocPDCH 11 & 18 & -0.03 & 16.04 & 0.93 & 0.01 & 15.93 & 0.97 \\
\hline ocPDCH 18 & 38 & $0.89 *$ & 339.59 & 1.90 & $0.89 *$ & 338.10 & 1.90 \\
\hline ocPDCH 19 & 31 & $0.70 *$ & 17.41 & 1.13 & $0.70^{*}$ & 17.33 & 1.13 \\
\hline ocPDCH 20 & 16 & -0.17 & 6.15 & 0.42 & -0.15 & 6.88 & 0.49 \\
\hline ocPDCH 21 & 18 & $0.62 *$ & 26.79 & 1.44 & $0.61 *$ & 27.15 & 1.44 \\
\hline ocPDCH 30 & 18 & 0.33 & 19.11 & 1.28 & 0.33 & 18.95 & 1.28 \\
\hline ocPDCH 31 & 18 & -0.34 & 6.92 & 0.20 & -0.34 & 6.86 & 0.19 \\
\hline ocPDCH 32 & 14 & -0.12 & 23.94 & -1.08 & -0.12 & 22.15 & -0.99 \\
\hline ocPDCH 33 & 35 & 0.21 & 4.79 & 0.19 & 0.19 & 6.16 & 0.72 \\
\hline ocPDCH all & 346 & $0.15^{*}$ & 17.53 & 0.42 & $0.15^{* *}$ & 17.40 & 0.44 \\
\hline
\end{tabular}

and PTCH 8. The fractional bias $F$ varies from a strong overestimation by the model over reasonable values to a strong underestimation. Significant correlations $r$ are obtained only for four releases from STC, seven releases from GGW, and the analysis for all releases combined from both STC and GGW. The correlations $r$ are high for ocPDCH 18, ocPDCH 19, and PTCH 23, and they are low for the analysis for all releases together (ocPDCH all and PTCH all). Note that the aircraft mostly flew crosswind through the plumes. Therefore, if the modeled plume is somewhat too slow or somewhat too fast, the agreement between the model and the measurements can be very bad, although the model captures the overall plume structure and the pathway. Sensitivity studies showed that the statistical numbers presented here are considerably affected and some of them can be improved, if another averaging interval is used for the model output (here, we used $30 \mathrm{~min}$ ).

Some statistical parameters for the run with convection differ from those for the run without convection. For all parameters for PTCH 18 and for $E$ and $F$ for $\mathrm{PDCH} 33$, the convection seems to improve the statistics, but there are also cases in which the convection seems to worsen the results-for instance, for PTCH 32 and PDCH 32 (Table 4 and Table 5). These are, however, only very few cases relative to the total number of releases and measurements, and the differences between runs with and without convection are small. Thus, from ANATEX it cannot be concluded that the convection scheme improves or worsens the agreement
TABLE 5. Analysis of model results against aircraft measurements from all flights for the PTCH releases at GGW during ANATEX; $N$ indicates the number of data points. Coefficients $r$ that are significantly positive on a confidence level of $95 \%$ are indicated by an asterisk.

\begin{tabular}{|c|c|c|c|c|c|c|c|}
\hline \multirow[b]{2}{*}{ Release } & \multirow[b]{2}{*}{$N$} & \multicolumn{3}{|c|}{ Conv } & \multicolumn{3}{|c|}{ Noconv } \\
\hline & & $r$ & $E$ & $F$ & $r$ & $E$ & $F$ \\
\hline PTCH 3 & 19 & -0.17 & 10.44 & 0.36 & -0.16 & 10.42 & 0.32 \\
\hline PTCH 4 & 20 & $0.37 *$ & 14.81 & -1.20 & $0.37 *$ & 14.92 & -1.20 \\
\hline РTCH 7 & 40 & -0.08 & 24.42 & -0.62 & -0.07 & 24.35 & -0.62 \\
\hline РТCH 8 & 40 & -0.05 & 199.94 & -1.75 & -0.05 & 202.19 & -1.75 \\
\hline РTCH 10 & 27 & -0.04 & 90.82 & 1.03 & -0.03 & 91.63 & 1.04 \\
\hline РTCH 11 & 39 & -0.03 & 18.33 & 0.32 & -0.03 & 18.32 & 0.32 \\
\hline РTCH 12 & 16 & 0.14 & 9.15 & 1.17 & 0.14 & 9.17 & 1.17 \\
\hline РTCH 13 & 20 & 0.33 & 4.37 & 0.39 & 0.33 & 4.34 & 0.39 \\
\hline РTCH 14 & 37 & -0.17 & 56.59 & 1.78 & -0.17 & 56.79 & 1.78 \\
\hline РТCH 17 & 40 & -0.13 & 7.38 & 0.22 & -0.13 & 7.38 & 0.22 \\
\hline РTCH 18 & 40 & $0.44 *$ & 14.45 & -1.36 & $0.40 *$ & 16.17 & -1.40 \\
\hline РTCH 20 & 39 & -0.15 & 34.77 & 0.60 & -0.15 & 34.45 & 0.60 \\
\hline РТCH 21 & 32 & -0.06 & 18.42 & 0.64 & -0.06 & 18.44 & 0.64 \\
\hline РTCH 23 & 60 & $0.69 *$ & 4.55 & 0.91 & $0.69 *$ & 4.52 & 0.91 \\
\hline РTCH 24 & 80 & $0.58^{*}$ & 37.19 & 0.67 & $0.57 *$ & 37.13 & 0.67 \\
\hline РTCH 25 & 20 & $0.55^{*}$ & 2.94 & -0.04 & $0.55^{*}$ & 2.91 & -0.04 \\
\hline РTCH 26 & 28 & $0.43^{*}$ & 7.60 & 1.02 & $0.43^{*}$ & 7.61 & 1.01 \\
\hline РTCH 27 & 37 & -0.26 & 8.02 & 0.40 & -0.27 & 8.22 & 0.42 \\
\hline РTCH 30 & 60 & -0.03 & 43.38 & 1.63 & -0.04 & 45.39 & 1.62 \\
\hline РTCH 32 & 76 & $0.43^{*}$ & 18.06 & -0.47 & $0.45^{*}$ & 16.14 & -0.34 \\
\hline РTCH 33 & 40 & 0.12 & 29.98 & -1.02 & 0.12 & 30.21 & -1.03 \\
\hline PTCH all & 908 & $0.14 *$ & 18.43 & 0.44 & $0.14 *$ & 18.30 & 0.44 \\
\hline
\end{tabular}

between model results and measurements. Many more measurements at higher altitudes and under conditions with considerable convective activity are necessary.

\section{Comparison with ${ }^{222} \mathrm{Rn}$ measurements}

Because it was difficult to draw sound conclusions on the performance of the EZ99 scheme from the tracer experiments, we referred back to ${ }^{222} \mathrm{Rn}$ measurements. The radionuclide ${ }^{222} \mathrm{Rn}$ is a decay product of ${ }^{238} \mathrm{U}$ and is mainly exhaled from land surfaces. Its main sink is radioactive decay. Because of its half-life of only 3.824 days, the spatial and, especially, the vertical, distributions of ${ }^{222} \mathrm{Rn}$ are highly sensitive to subgrid-scale processes such as deep convection. Therefore, ${ }^{222} \mathrm{Rn}$ is widely used as a tracer in atmospheric transport models to validate parameterizations of such processes (e.g., Dentener et al. 1999; Jacob et al. 1997; Feichter and Crutzen 1990).

However, while during the tracer experiments CAPTEX and ANATEX the emissions were exactly known the emissions of ${ }^{222} \mathrm{Rn}$ are uncertain, because they vary greatly with soil conditions and meteorological factors (Turekian et al. 1977; Dörr 1984). Flux measurements of ${ }^{222} \mathrm{Rn}$ show a large spread of continental emissions 
ranging from 0.1 to 2.5 atoms $\mathrm{cm}^{-2} \mathrm{~s}^{-1}$, with a best estimate of 1.2 atoms cm $\mathrm{cm}^{-2} \mathrm{~s}^{-1}$ (Turekian et al. 1977).

Because it is difficult to extrapolate these point measurements to larger areas, most model studies use a global continental emission of 1 atom $\mathrm{cm}^{-2} \mathrm{~s}^{-1}$. On a global scale, this emission may be accurate to within $25 \%$; on a regional scale, it may be accurate to within a factor of 2 (e.g., Jacob et al. 1997). Whether this accuracy is good enough for a model validation is questionable, but because ${ }^{222} \mathrm{Rn}$ measurements are widely used for model validation, we will present comparisons of ${ }^{222} \mathrm{Rn}$ data with FLEXPART results for completeness.

We use $11^{222} \mathrm{Rn}$ profiles from the Moffett Field campaign between June and August 1994 and $9{ }^{222}$ Rn profiles from the North Atlantic Regional Experiment (NARE) in August 1993, all measured by aircraft, to test the EZ99 scheme in FLEXPART. The NARE campaign took place along North American east coast to measure the pollution outflow from the North American continent (Fehsenfeld et al. 1996). The ${ }^{222} \mathrm{Rn}$ profiles were taken at altitudes ranging from 500 to about $5000 \mathrm{~m}$ MSL (Zaucker et al. 1996). During the Moffett Field campaign, measurements of ${ }^{222} \mathrm{Rn}$ were taken along the California coast with the purpose of acquiring a statistically significant dataset, at one season and location, suitable for use in the development and validation of chemical transport models (Kritz et al. 1998; Stockwell et al. 1998). The profiles cover the entire troposphere up to $12600 \mathrm{~m}$ above sea level. Thus, the Moffett Field and NARE campaigns both provide more measurements above the ABL than do the tracer experiments during CAPTEX and ANATEX.

For our simulations we have used ${ }^{222} \mathrm{Rn}$ emissions of 1 atom $\mathrm{cm}^{-2} \mathrm{~s}^{-1}$ between $60^{\circ} \mathrm{S}$ and $60^{\circ} \mathrm{N}$, and one-half of this amount between $60^{\circ}$ and $70^{\circ} \mathrm{N}(\mathrm{S})$ as recommended by Jacob et al. (1997). Emissions over oceans and poleward of $70^{\circ}$ are assumed to be small and are therefore neglected. From each aircraft measurement (receptor), we released 20000 particles with unit mixing ratio and followed them 20 days backward in time. A response function to emission input $\left(\mathrm{s} \mathrm{m}^{3} \mathrm{~kg}^{-1}\right)$, which is proportional to the particles residence times, is calculated on a $0.5^{\circ} \times 0.5^{\circ}$ grid. The response function in the lowest model layer multiplied with the ${ }^{222} \mathrm{Rn}$ source strength (compiled to $\mathrm{kg} \mathrm{m}^{-3} \mathrm{~s}^{-1}$ ) gives the ${ }^{222} \mathrm{Rn}$ source contribution per grid box. By summing up the source contributions over all grid boxes we obtain the mass mixing ratio at the receptor. Simulations with and without convection were performed, and the resulting modeled mixing ratios were compared with the measured mixing ratios.

Figure 11 shows a comparison of the mean measured (a) MOFFETT FIELD 1994 MEAN PROFILES

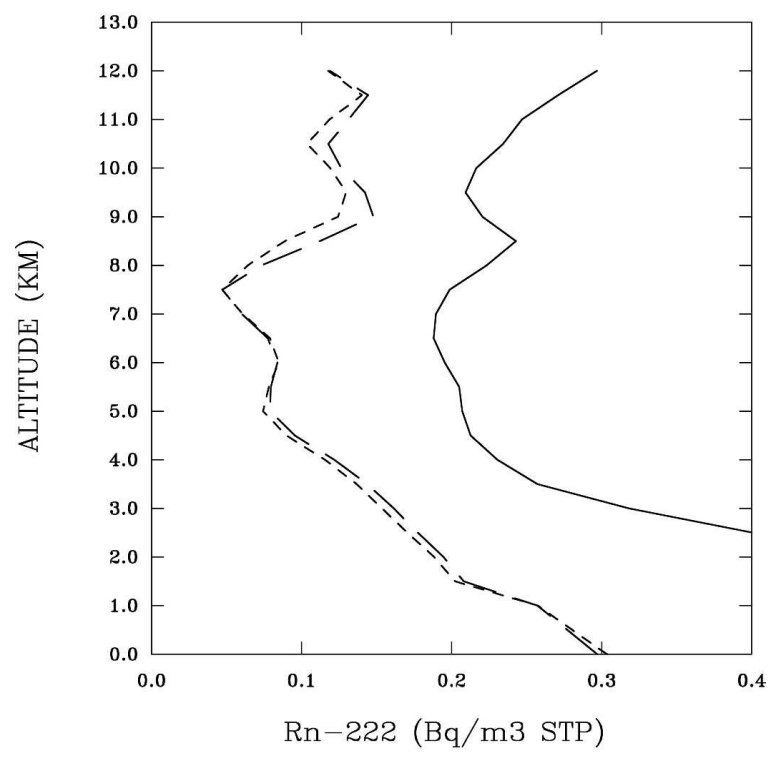

(b)

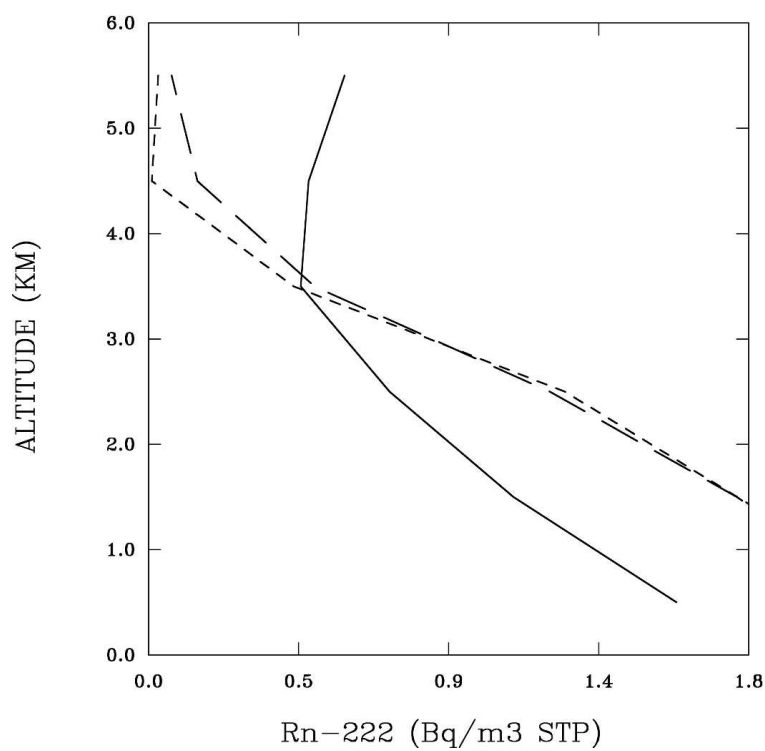

FIG. 11. Mean measured (solid line) and modeled ${ }^{222} \mathrm{Rn}$ profiles (Bq m${ }^{-3} \mathrm{~s}^{-1}$ STP) for (a) the Moffett Field and (b) the NARE campaign. The long-dashed and short-dashed lines represent results from the simulations with and without convection, respectively.

and modeled ${ }^{222} \mathrm{Rn}$ profiles for the Moffett Field and NARE campaigns. In the ABL, the simulations with and without convection both considerably underestimate the observations for the Moffett Field campaign and overestimate them for the NARE campaign. A reason for this might be the uncertainties in the ${ }^{222} \mathrm{Rn}$ emissions. In addition, both campaigns took place at 
TABLE 6. Analysis of model results against aircraft measurements from all flights during the Moffett Field campaign; $N$ indicates the number of data points. Coefficients $r$ that are significantly positive on a confidence level of $95 \%$ are indicated by an asterisk.

\begin{tabular}{|c|c|c|c|c|c|c|c|}
\hline \multirow[b]{2}{*}{ Date } & \multirow[b]{2}{*}{$N$} & \multicolumn{3}{|c|}{ Conv } & \multicolumn{3}{|c|}{ Noconv } \\
\hline & & $r$ & $E$ & $F$ & $\mathrm{r}$ & $E$ & $F$ \\
\hline 03 Jun 1994 & 11 & $0.77 *$ & 0.45 & -1.41 & $0.73 *$ & 0.49 & -1.45 \\
\hline 07 Jun 1994 & 12 & 0.32 & 0.49 & -1.26 & 0.17 & 0.72 & -1.68 \\
\hline 14 Jun 1994 & 14 & 0.28 & 1.79 & -4.03 & 0.35 & 2.24 & -4.96 \\
\hline 16 Jun 1994 & 13 & 0.11 & 1.20 & -3.06 & 0.004 & 1.46 & -3.56 \\
\hline 23 Jun 1994 & 11 & -0.14 & 3.07 & -5.45 & -0.13 & 1.72 & -2.65 \\
\hline 24 Jun 1994 & 11 & $0.85^{*}$ & 5.80 & -10.75 & 0.07 & 19.33 & -30.00 \\
\hline 28 Jun 1994 & 12 & 0.33 & 1.02 & -2.02 & 0.28 & 1.53 & -3.47 \\
\hline 07 Jul 1994 & 9 & $0.95 *$ & 0.89 & -2.62 & $0.95 *$ & 0.91 & -2.69 \\
\hline 10 Aug 1994 & 10 & $0.92 *$ & 0.86 & -2.29 & $0.87 *$ & 0.71 & -1.69 \\
\hline 12 Aug 1994 & 12 & 0.28 & 2.68 & -4.81 & -0.17 & 5.42 & -8.37 \\
\hline 16 Aug 1994 & 13 & -0.46 & 1.77 & 0.02 & -0.21 & 2.48 & -0.39 \\
\hline All & 128 & $0.77 *$ & 1.32 & -2.30 & $0.73^{*}$ & 1.65 & -2.71 \\
\hline
\end{tabular}

the edge of North America where the horizontal ${ }^{222} \mathrm{Rn}$ gradients are large. Because the modeled value greatly depends on whether the respective grid box is mainly located over land or over the sea, big differences can occur between modeled and measured values. In the free troposphere, the model underestimates the observations for both campaigns. For Moffett Field, such results were also found by other model studies (e.g., Jacob et al. 1997; Stockwell et al. 1998). Because the air masses in the free troposphere over California mainly come from eastern Asia where they were lifted by convection and subsequently transported over the Pacific in the subtropical jet, an anomalously high ${ }^{222} \mathrm{Rn}$ source in eastern Asia has been proposed as an explanation for the failure of the models (see Jacob et al. 1997, and references therein). However, this is just speculation and reflects the uncertainties in the ${ }^{222} \mathrm{Rn}$ emissions. Our model results agree with the measurements within a factor of 2-3, and they lie at least in the range of values found by other model studies (e.g., Jacob et al. 1997; Stockwell et al. 1998; Lin et al. 1996).

The mean profiles show that, at altitudes above the $\mathrm{ABL}$ and especially in the upper troposphere, the simulations including convection improve the comparison with the measurements (Fig. 11). This is also evident from Tables 6 and 7, which present the statistical parameters $r, E$, and $F$ for both campaigns. There are two flights of the Moffett Field campaign (23 June and 10 August) and three flights of the NARE campaign (17, 28, and 31 August), for which $E$ and $F$ get worse if the convection scheme is switched on. In all other cases they improve. This is also true for the significant correlations $r$, which are all above 0.5 . There is only one exception during the Moffett Field campaign (7 July)
TABLE 7. Analysis of model results against aircraft measurements from all flights during the NARE campaign; $N$ indicates the number of data points. Coefficients $r$ that are significantly positive on a confidence level of $95 \%$ are indicated by an asterisk.

\begin{tabular}{|c|c|c|c|c|c|c|c|}
\hline \multirow[b]{2}{*}{ Date } & \multirow[b]{2}{*}{$N$} & \multicolumn{3}{|c|}{ Conv } & \multicolumn{3}{|c|}{ Noconv } \\
\hline & & $R$ & $E$ & $F$ & $r$ & $E$ & $F$ \\
\hline 16 Aug 1993 & 9 & $0.97 *$ & 0.69 & 0.53 & $0.98 *$ & 0.95 & 0.36 \\
\hline 17 Aug 1993 & 8 & 0.20 & 17.57 & 1.78 & 0.19 & 17.26 & 1.76 \\
\hline 18 Aug 1993 & 6 & -0.01 & 0.10 & 0.52 & -0.01 & 3.42 & -8.18 \\
\hline 22 Aug 1993 & 6 & -0.83 & 2.70 & 0.99 & -0.96 & 3.14 & 1.11 \\
\hline 24 Aug 1993 & 5 & 0.77 & 1.09 & -0.13 & 0.09 & 1.40 & -0.78 \\
\hline 27 Aug 1993 & 6 & $0.87 *$ & 0.08 & 0.47 & $0.88 *$ & 0.11 & 0.55 \\
\hline 28 Aug 1993 & 8 & $0.94 *$ & 0.28 & -0.70 & $0.92 *$ & 0.15 & -0.60 \\
\hline 29 Aug 1993 & 9 & 0.60 & 1.05 & 0.36 & 0.58 & 1.31 & 0.45 \\
\hline 31 Aug 1993 & 9 & $0.60 *$ & 0.18 & 0.45 & $0.50 *$ & 0.17 & 0.39 \\
\hline All & 66 & $0.64 *$ & 0.73 & 0.52 & $0.62 *$ & 0.82 & 0.49 \\
\hline
\end{tabular}

and two exceptions during NARE (16 and 27 August) where $r$ hardly changes. The convection especially improves the results for the flight on 24 June during the Moffett Field campaign. The correlation $r$ gets significantly high and $E$ and $F$ decrease by about a factor of 3 . If only data above $7.5 \mathrm{~km}$ are accounted for when calculating the statistical parameters for all Moffett Field flights (63 data points), $r=0.68, E=1.57$, and $F=-2.50$ without convection and $r=0.74, E=1.17$, and $F=-2.01$, including convection. Overall, it can be concluded from both campaigns that including convection in the model simulations has a positive effect on the comparison between measurements and model results.

\section{Summary and conclusions}

The Lagrangian particle dispersion model FLEXPART, version 6.2 (Stohl et al. 2005), has been equipped with the convective parameterization scheme by EZ99. The parameterization requires as input the grid-scale temperature and humidity as well as the convective cloud base mass flux $M_{\mathrm{cb}}$ from the previous time step and then calculates a mass flux matrix giving the necessary information for the convective redistribution of the particles. The interface between FLEXPART and the EZ99 scheme has been tested, and the results from model runs with and without convection have been compared with tracer experiment and ${ }^{222} \mathrm{Rn}$ data.

We showed that if a tracer is well mixed in an atmospheric column then it remains so after the convective redistribution of the particles. Test runs with particles carrying the atmospheric mass showed only minor fluctuations in the mass profiles resulting from the stochastic redistribution of the particles by convection.

For practical reasons, the EZ99 scheme was imple- 
mented in a way that results in small differences in the convective particle redistribution between forward and backward simulations in time. The magnitude of these differences depends on the synchronization time step in FLEXPART. For a time step of $900 \mathrm{~s}$, we showed that the mean relative deviation of the mass fluxes of a forward simulation from those of a backward simulation is $2.84 \%$. Smaller time steps result in smaller relative deviations. We conclude therefore that our implementation results in only minor differences between forward and backward simulations, which can be tolerated given the large overall uncertainties of convective parameterizations.

We compared the convective upward mass fluxes and precipitation rates with those archived in the ERA-40 data. The largest differences between the convective upward mass fluxes can be seen in the lower troposphere, where the mass fluxes from the ECMWF scheme show larger values, and in the middle and upper troposphere north and south of the intertropical convergence zone, where the EZ99 scheme shows larger mass fluxes. In a global mean the convective upward mass fluxes of the ECMWF scheme are larger than those from the EZ99 scheme by $26 \%$. A similar result is obtained for the global mean convective precipitation rate, which is lower in the EZ99 scheme by $24 \%$. If the convective precipitation from the EZ99 scheme is combined with the large-scale precipitation from the ERA40 data, the resulting total precipitation is closer to the observations from the Global Precipitation Climatology Project than is the total precipitation from the ERA-40 data. We cannot conclude that the EZ99 scheme that diagnoses convection offline produces better results than the ECMWF scheme that runs online in the ECMWF model, but we could at least show that the EZ99 scheme gives acceptable results within FLEXPART.

Last, we evaluated the convective transport in FLEXPART by using large-scale tracer experiment and ${ }^{222} \mathrm{Rn}$ data. We compared aircraft measurements from the tracer experiments CAPTEX (Ferber et al. 1986) and ANATEX (Draxler et al. 1991) with model simulations with and without convection. Within the atmospheric boundary layer no significant differences were found between the runs with and without convection, because there the effects of convection are dominated by the boundary layer parameterization. At higher altitudes, the model runs with convection revealed better agreement with the measurements for some flights during CAPTEX, but in the other cases the results were indifferent. These findings can, however, not be generalized, because the tracer experiments took place in seasons of the year during which convec- tion is weak. In addition, too few measurements were available above the ABL. To validate the convection scheme in FLEXPART properly, many more measurements at higher altitudes and under conditions with considerable convective activity would be necessary. However, no tracer experiments providing such measurements exist to our knowledge. Therefore, we used ${ }^{222} \mathrm{Rn}$ profiles measured by aircraft from the Moffett Field 1994 and the NARE 1993 campaigns. Both campaigns provide ${ }^{222} \mathrm{Rn}$ measurements at higher altitudes and took place in summer. A comparison of the mean measured profiles with the simulated profiles and a statistical evaluation of the single flights revealed that for both campaigns the model results compare better to the measurements when the convection scheme is switched on. However, the modeled profiles both with and without convection agree with the measurements by only a factor of 2-3, a result that has also been found by other studies. One reason is that, in regions with sharp ${ }^{222} \mathrm{Rn}$ gradients, the modeled value greatly depends on whether the respective grid box is mainly located over the region with high or low ${ }^{222} \mathrm{Rn}$ values. Another presumably much more important reason is that the emissions of ${ }^{222} \mathrm{Rn}$ are uncertain, because they greatly vary with meteorological and soil conditions. On a global scale, the ${ }^{222} \mathrm{Rn}$ emissions may be accurate to within $25 \%$; on a regional scale, they are accurate to within a factor of 2 (e.g., Jacob et al. 1997). We doubt that this accuracy is good enough for a thorough model validation, and our conclusion is that all datasets available to date are not sufficient for a validation of vertical transport in models. Either the emissions are exactly known but too few data are available as is the case for the tracer experiments, or a comprehensive dataset is available but the emissions are uncertain as is the case for the ${ }^{222} \mathrm{Rn}$ measurements. There is a clear need for the establishment of datasets providing both tropospheric profiles and reliable emission information for a tracer, such that the data are suitable for the validation of vertical transport in models.

Acknowledgments. We thank ECMWF and Met.no in Oslo, Norway, for permitting access to the ECMWF data. The user support at ECMWF is greatly acknowledged. Doctor R. Draxler gave us access to the CAPTEX and ANATEX data and patiently answered questions concerning the data. NILU and the Insitute of Meteorology at BOKU are supported by the EU FP6 Network of Excellence ACCENT. BOKU is also supported by the project P17924 of FWF.

\section{REFERENCES}

Arakawa, A., 2004: The cumulus parameterization problem: Past, present, and future. J. Climate, 17, 2493-2525. 
—, and W. H. Schubert, 1974: Interaction of a cumulus cloud ensemble with the large-scale environment, Part I. J. Atmos. Sci., 31, 674-701.

Charney, J. G., and A. Eliassen, 1964: On the growth of the hurricane depression. J. Atmos. Sci., 21, 68-75.

Collins, W. J., R. D. Derwent, C. E. Johnson, and D. S. Stevenson, 2002: A comparison of two schemes for the convective transport of chemical species in a Lagrangian global chemistry model. Quart. J. Roy. Meteor. Soc., 128, 991-1009.

Cotton, W. R., and R. A. Anthes, 1992: Storm and Cloud Dynamics. Academic Press, 883 pp.

__, R. D. Alexander, R. Hertenstein, R. L. Walko, R. L. McAnelly, and M. Nicholls, 1995: Cloud venting-A review and some new global annual estimates. Earth-Sci. Rev., 39, 169-206.

Dentener, F., J. Feichter, and A. Jeuken, 1999: Simulation of the transport of $\mathrm{Rn}^{222}$ using on-line and off-line global models at different horizontal resolutions: A detailed comparison with measurements. Tellus, 51B, 573-602.

Dörr, H., 1984: Investigation of the gas and water budgets in the unsaturated soil layer using carbon dioxide and radon 222 (in German). Ph.D. thesis, Universität Heidelberg, 87 pp.

Draxler, R. R., R. Dietz, R. J. Lagomarsino, and G. Start, 1991: Across North America Tracer Experiment (ANATEX) sampling and analysis. Atmos. Environ., 25A, 2815-2836.

Emanuel, K. A., 1986: An air-sea interaction theory for tropical cyclones. Part I: Steady-state maintenance. J. Atmos. Sci., 43, 585-604.

, 1991: A scheme for representing cumulus convection in large-scale models. J. Atmos. Sci., 48, 2313-2335.

_ 1994: Atmospheric Convection. Oxford University Press, 580 pp.

, and D. J. Raymond, Eds., 1993: The Representation of $\mathrm{Cu}$ mulus Convection in Numerical Models. Meteor. Monogr., No. 46, Amer. Meteor. Soc., 246 pp.

—_, and M. Živković-Rothman, 1999: Development and evaluation of a convection scheme for use in climate models. $J$. Atmos. Sci., 56, 1766-1782.

— D. Neelin, and C. S. Bretherton, 1994: On large-scale circulations in convecting atmospheres. Quart. J. Roy. Meteor. Soc., 120, 1111-1143.

Fehsenfeld, F. C., P. Daum, W. R. Leaitch, M. Trainer, D. D. Parrish, and G. Hbler, 1996: Transport and processing of $\mathrm{O}_{3}$ and $\mathrm{O}_{3}$ precursors over the North Atlantic: An overview of the 1993 North Atlantic Regional Experiment (NARE) summer intensive. J. Geophys. Res., 101, 28 877-28 892.

Feichter, J., and P. J. Crutzen, 1990: Parameterization of vertical tracer transport due to deep cumulus convection in a global transport model and its evaluation with ${ }^{222}$ Radon measurements. Tellus, 42B, 100-117.

Ferber, G. J., J. L. Heffter, R. R. Draxler, R. J. Lagomarisino, F. L. Thomas, R. N. Dietz, and C. M. Benkwitz, 1986: CrossAppalachian Tracer Experiment (CAPTEX 83). Final report, NOAA Air Research Laboratories Tech. Memo. ERL ARL142, 60 pp.

Forster, C., and Coauthors, 2001: Transport of boreal forest fire emissions from Canada to Europe. J. Geophys. Res., 106, 22 887-22 906.

—_, and Coauthors, 2004: Lagrangian transport model forecasts and a transport climatology for the Intercontinental Transport and Chemical Transformation 2002 (ITCT 2k2) measurement campaign. J. Geophys. Res., 109, D07S92, doi:10.1029/2003JD003589.
Frank, W. M., 1978: The life cycle of GATE convective systems. $J$ Atmos. Sci., 35, 1256-1264.

Gregory, D., J.-J. Morcrette, C. Jacob, A. C. M. Beljaars, and T. Stickdale, 2000: Revision of convection, radiation, and cloud schemes in the ECMWF integrated forecasting system. Quart. J. Roy. Meteor. Soc., 126, 1685-1710.

Jacob, D. J., and Coauthors, 1997: Evaluation and intercomparison of global atmospheric transport models using ${ }^{222} \mathrm{Rn}$ and other short-lived species. J. Geophys. Res., 102, 5953-5970.

James, P., A. Stohl, C. Forster, S. Eckhardt, P. Seibert, and A. Frank, 2003a: A 15-year climatology of stratospheretroposphere exchange with a Lagrangian particle dispersion model: 1. Methodology and validation. J. Geophys. Res., 108, 8519, doi:10.1029/2002JD002637.

$-,-\longrightarrow,-,-$, and,- 2003b: A 15-year climatology of stratosphere-troposphere exchange with a Lagrangian particle dispersion model: 2. Mean climate, seasonal and interannual variability. J. Geophys. Res., 108, 8522, doi:10.1029/2002JD002639.

Kållberg, P., P. Berrisford, B. Hoskins, A. Simmmons, S. Uppala, S. Lamy-Thépaut, and R. Hine, 2005: ERA-40 Atlas. Vol. 19, ERA-40 Project Report Series, ECMWF, 191 pp.

Kritz, M. A., S. W. Rosner, and D. Z. Stockwell, 1998: Validation of an off-line three-dimensional chemical transport model using observed radon profiles 1. Observations. J. Geophys. Res., 103, 8425-8432.

Lelieveld, J., and P. J. Crutzen, 1994: Role of deep cloud convection in the ozone budget of the troposphere. Science, 264, 1759-1761.

Lin, X., F. Zaucker, E.-Y. Hsie, M. Trainer, and S. A. McKeen, 1996: Radon 222 simulations as a test of a three-dimensional regional transprort model. J. Geophys. Res., 101, $29165-$ 29177.

Luhar, A. K., M. F. Hibberd, and P. J. Hurley, 1996: Comparison of closure schemes used to specify the velocity PDF in Lagrangian stochastic dispersion models for convective conditions. Atmos. Environ., 30, 1407-1418.

Manabe, S., and R. F. Strickler, 1964: Thermal equilibrium of the atmosphere with a convective adjustment. J. Atmos. Sci., 21, 361-385.

Nordeng, T. E., 1994: Extended versions of the convective parameterization scheme at ECMWF and their impact on the mean and transient activity of the model in the tropics. ECMWF Research Department Tech. Memo. 206, 41 pp.

Olivié, D. J. L., P. F. J. van Velthoven, A. C. M. Beljaars, and H. M. Kelder, 2004: Comparison between archived and offline diagnosed convective mass fluxes in the chemistry transport model TM3. J. Geophys. Res., 109, D11303, doi:10.1029/ 2003JD004036.

Ooyama, K. V., 1964: A dynamical model for the study of tropical cyclone development. Geofis. Int., 4, 187-198.

, 1969: Numerical simulation of the life cycle of tropical cyclones. J. Atmos. Sci., 26, 3-40.

- 1982: Conceptual evolution of the theory and modelling of the tropical cyclone. J. Meteor. Soc. Japan, 60, 369-379.

Raymond, D. J., 1995: Regulation of moist convection over the West Pacific warm pool. J. Atmos. Sci., 52, 3945-3959.

_ , and A. M. Blyth, 1986: A stochastic model for nonprecipitating cumulus clouds. J. Atmos. Sci., 43, 2708-2718.

Reithmeier, C., and R. Sausen, 2002: ATTILA: Atmospheric tracer transport in a Lagrangian model. Tellus, 54B, 278-299. 
Riehl, H., and J. S. Malkus, 1959: On the heat balance of the equatorial through zone. Geophysica, 6, 503-538.

Seibert, P., and A. Frank, 2004: Source-receptor matrix calculation with a Lagrangian particle dispersion model in backward mode. Atmos. Chem. Phys., 4, 51-63.

_, B. Krüger, and A. Frank, 2001: Parametrisation of convective mixing in a Lagrangian particle dispersion model. Proc. Fifth GLOREAM Workshop, Wengen, Switzerland, EUROTRAC-2, 8 pp.

Smith, R. K., 1997a: On the theory of CISK. Quart. J. Roy. Meteor. Soc., 123, 407-418.

_ 1997b: The physics and the parameterization of moist atmospheric convection. Series C: Mathematical and Physical Sciences, R. K. Smith, Ed., NATO ASI Series, Vol. 5, Kluwer Academic in cooperation with NATO Scientific Affairs Division, $498 \mathrm{pp}$.

Spichtinger, N., M. Wenig, P. James, T. Wagner, U. Platt, and A. Stohl, 2001: Satellite detection of a continental-scale plume of nitrogen oxides from boreal forest fires. Geophys. Res. Lett., 28, 4579-4582.

Stockwell, D. Z., M. A. Kritz, M. P. Chipperfield, and J. A. Pyle, 1998: Validation of an off-line three-dimensional chemical transport model using observed radon profiles 2. Model results. J. Geophys. Res., 103, 8433-8445.

Stohl, A., and D. J. Thomson, 1999: A density correction for Lagrangian particle dispersion models. Bound.-Layer Meteor., 90, 155-167.

—_, and T. Trickl, 1999: A textbook example of long-range transport: Simultaneous observation of ozone maxima of stratospheric and North American origin in the free troposphere over Europe. J. Geophys. Res., 104, 30 445-30 462.

, and P. James, 2004: A Lagrangian analysis of the atmospheric branch of the global water cycle. Part I: Method de- scription, validation, and demonstration for the August 2002 flooding in Central Europe. J. Hydrometeor., 5, 656-678.

- M. Hittenberger, and G. Wotawa, 1998: Validation of the Lagrangian particle dispersion model FLEXPART against large scale tracer experiment data. Atmos. Environ., 24, 4245-4264.

_ C. Forster, A. Frank, P. Seibert, and C. Wotawa, 2005: Technical note: The Lagrangian particle dispersion model FLEXPART version 6.2. Atmos. Chem. Phys., 5, 2461-2474.

Stunder, B. J. B., and R. R. Draxler, 1989: Across North America Tracer Experiment (ANATEX). Vol. Aircraft-based sampling. NOAA Tech. Memo. ERL ARL-177, 29 pp.

Telford, J. W., 1975: Turbulence, entrainment and mixing in cloud dynamics. Pure Appl. Geophys., 113, 1067-1084.

Thomson, D. J., 1987: Criteria for the selection of stochastic models of particle trajectories inturbulent flows. J. Fluid Mech., 180, 529-556.

Tiedtke, M., 1989: A comprehensive mass flux scheme for cumulus parameterization in large-scale models. Mon. Wea. Rev., 117, 1779-1800.

1993: Representation of cumulus clouds in large-scale models. Mon. Wea. Rev., 121, 3040-3061.

Turekian, K. K., Y. Nozaki, and L. Benninger, 1977: Cheochemistry of atmospheric radon and radon product. Annu. Rev. Earth Planet. Sci., 5, 227-255.

Wotawa, G., and M. Trainer, 2000: The influence of Canadian forest fires on pollutant concentrations in the United States. Science, 288, 324-328.

Zaucker, F., P. H. Daum, U. Wetterauer, C. Berkowitz, B. Kromer, and W. S. Broecker, 1996: Atmospheric ${ }^{222}$ Rn measurements during the 1993 NARE Intensive. J. Geophys. Res., 101, 29 149-29164. 